\title{
في ظل إستراتيجية تطوير السياحة الجزائرية أثر النشاط السياحي على النمو الاقتصادي
}

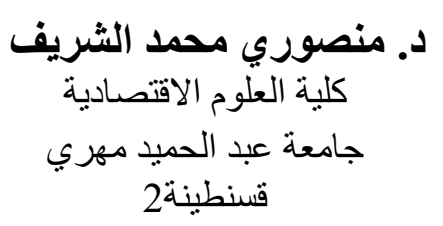

عرفت السياحة الدولية تطورات جدة معند

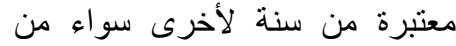

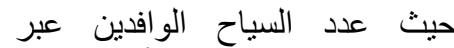
الحدود الجغر افية للبلدان، أو من حيث الونيث

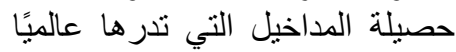

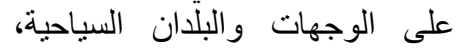
وجاءت هذه التطورات بفضل ذلت التك

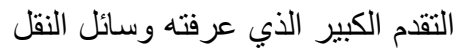

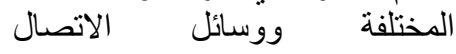
التكنولوجية الحديثة التي جعلت العالم بمثابة قرية صغيرة، ينتقل السائح فيها

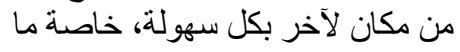

يعالج هذا المقال الأثر الإيجابي للسياحة على النمو الاقتصادي لادى البلدان

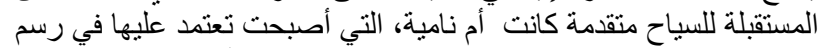

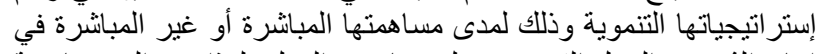

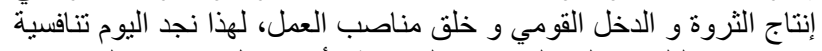

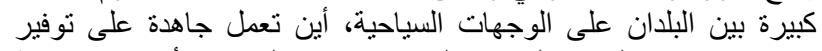

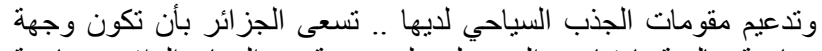

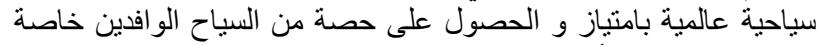

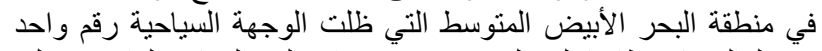

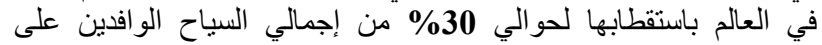

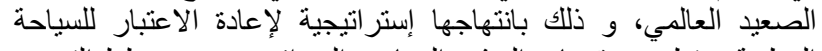

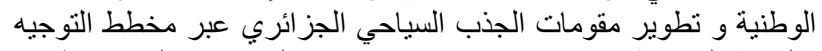

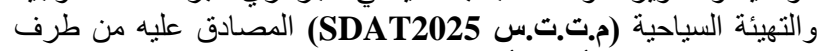

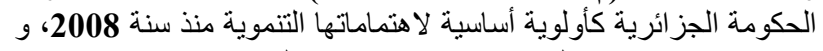

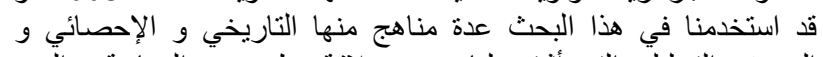

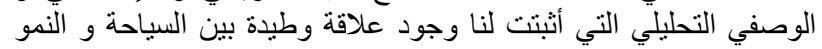

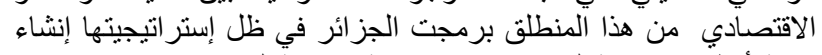

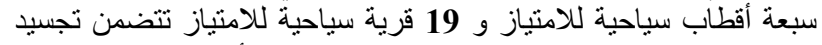

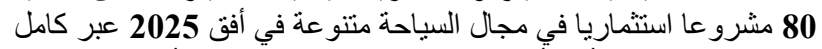

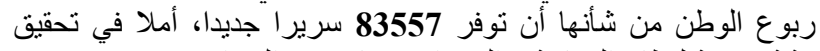

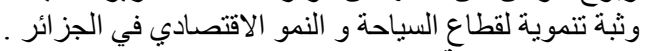

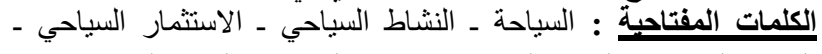
الوجهة السياحية ـ الجذب السياحي ـ مخطط التوجيه و التهيئة ـ التئة السياحية التئية

\begin{abstract}
:
This article treats the positive effects of Tourism on economic growth in developed and developing countries, which work to involve it within their strategies of development, because they consider that tourism has been contributing directly or indirectly on the creation of wealth, national income, and creating employment opportunities. For such reasons, countries work hardly in order to find ways of attractiveness in tourism sector. Algeria like any other countries makes a lot of efforts in being globally attractive enough for touristic people, especially within Mediterranean Sea. This place is classified as a number one for tourism, where $\mathbf{3 0 \%}$ of global tourism is oriented to.
\end{abstract}


بين أهم المناطق استقطابًا للسياح (أوروبا_الأمريكيتين_آسيا

والباسيفيكي) التي تسيطر لوحدها على أكثر من 90\%

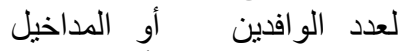
السياحية الدولية أين ضين التين منطقة البحر المتوسط تحتل الصدارة في قدرتها على جذب البح السياح وكوجهة سياحية عالمية بامتياز، حيث تستقطب لوحدها

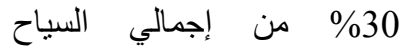
الو افدين ومن المداخيل، كما الجيا أصبحت السياحة الدولية تحنل مراتب جد متقدمة من بين أهم الهم الهية

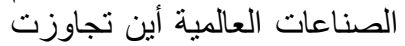
في الترتيب بعض الصناعات

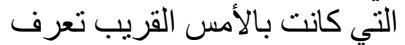

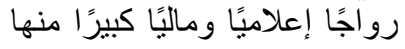

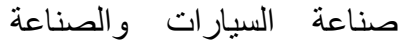
الغذائية، وهي اعنة اليوم تضاريات صناعات ريادية عالميًا
Then, it is for Algeria to reconsider its strategies of national tourism and its potential attractiveness by applying a program scheme launched by the government. Since 2008, the objective was to put tourism on top priorities of the economic development, It has used several approaches in the study, including historical, statistical and analytical descriptive, which proved to us a strong relationship between tourism and economic growth. In this context, Algeria has programmed seven tourism poles for excellence and $\mathbf{1 9}$ tourist villages for excellence, including the embodiment of $\mathbf{8 0}$ investment projects in the field of A variety of tourism in $\mathbf{2 0 2 5}$ across the whole country will provide $\mathbf{8 3 5 5 7}$ new beds, hoping to achieve a developmental leap for the tourism sector and economic growth in Algeria.

Kevwords: Tourism - Tourism ActivityTourism Investment- Tourism Destination Tourism attractiveness - Master Plan of Tourist Planning

كالصناعة الكيماوية والبترولية، من هذا المنطلق نجد اليوم الكثير من البلدان متقدمة كانت أو نامية تعتمد

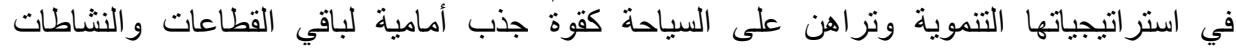

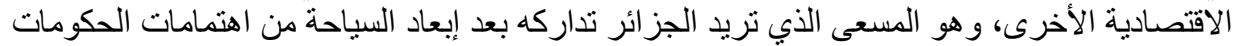

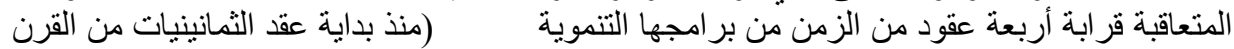

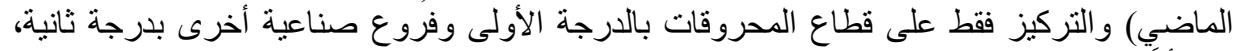

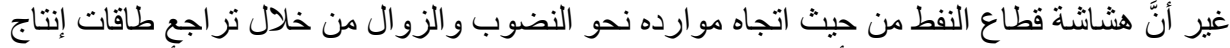

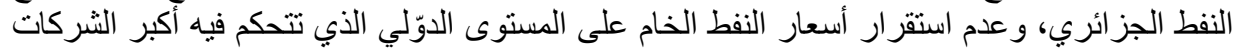

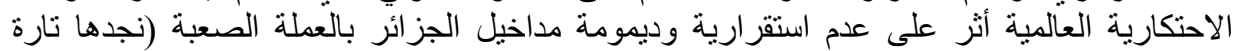
تتحسن وتتهار تارة أخرى).

لهذا تعيّن على الدولة الجزائرية العودة من جديد وبجدية الإهتمام بقطاع السياحة و إعطائه الأولوية في

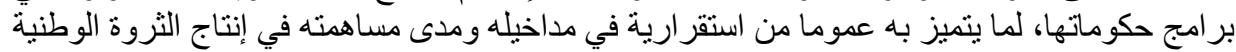

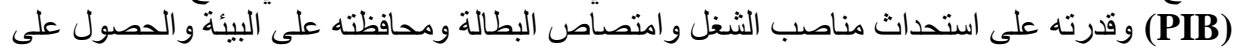
حصة من الأسو اق العالمية خاصة السوق المتوسطية بجعل الجز ائر وجهة سياحية تنافسية على الصعيد 
الإشكالية: ممّا سبق يتبلور لنا التساؤل الرئيسي لهذا المقال مفاده:

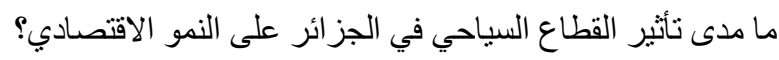

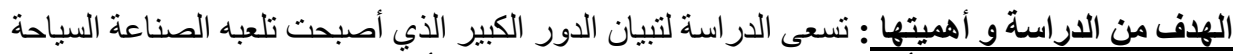

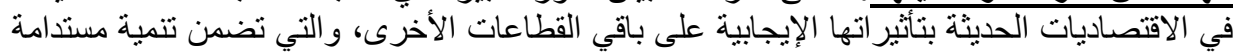

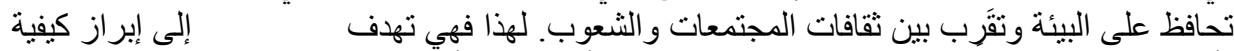

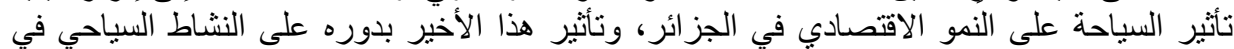

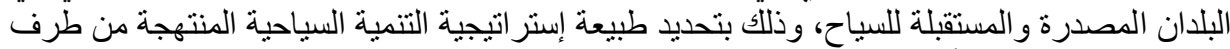
الجزائر للاندماج في الأسو اق العالمية.

الفرضية: يقوم هذا البحث على فرضية أساسية كون السياحة كباقي القطاعات الاقتصادية الأخرى تؤثر

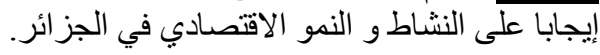

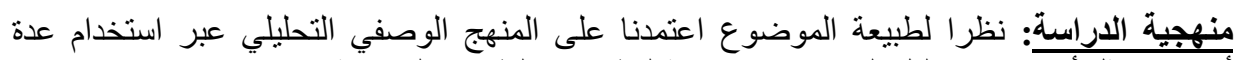

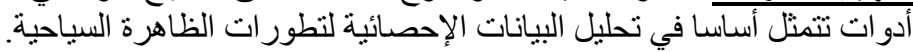

1. ت تعريف السياحة

تقدم المنظمة العالمية للسياحة تعريفًا تقنيًا على أنها: "مجموع النشاطات التي يقوم بها الأثخاص أثناء

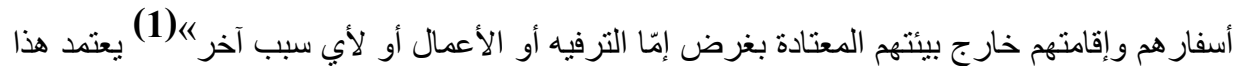

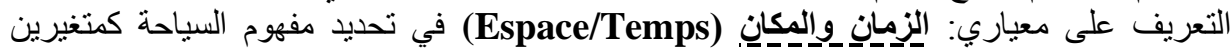

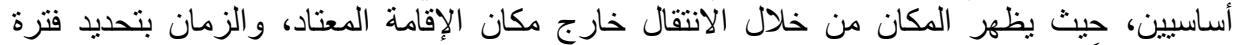

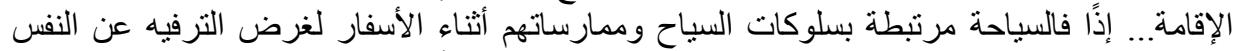

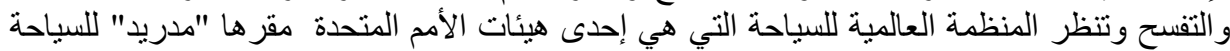

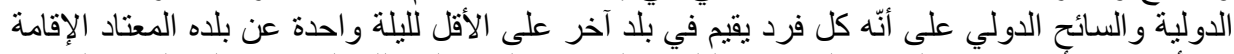

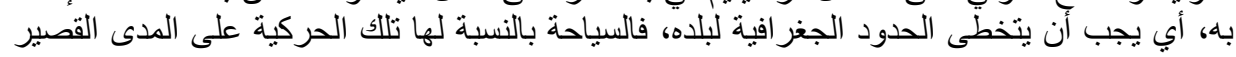

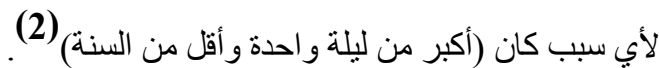

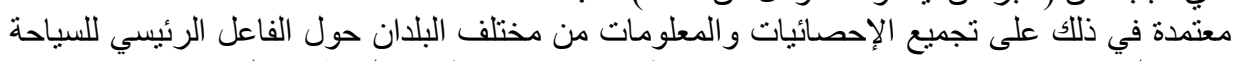

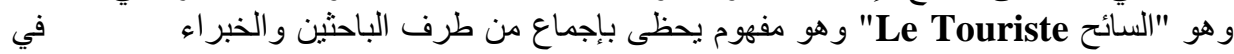

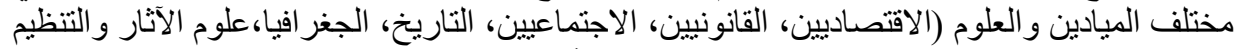

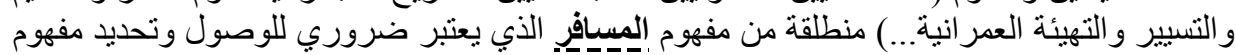

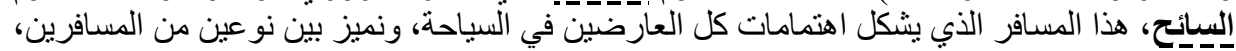

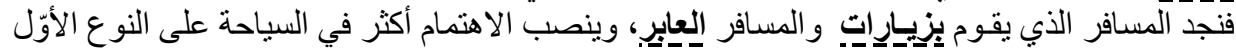

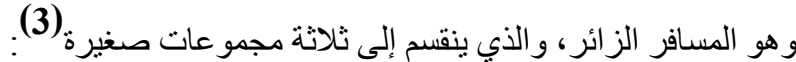

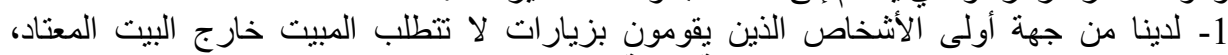

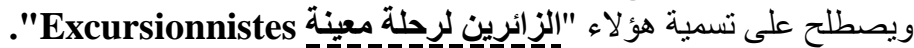
2- الأثخاص الذين ينجر عن تتقلاتهم وسفرياتهم المبييت على الأقل ثلاثة ليالي متتابعة عن مقر سكناهم

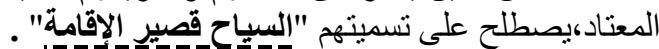

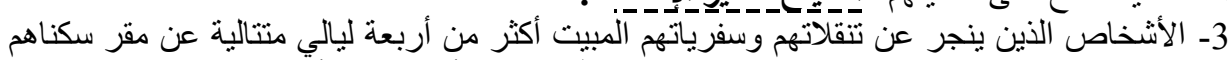

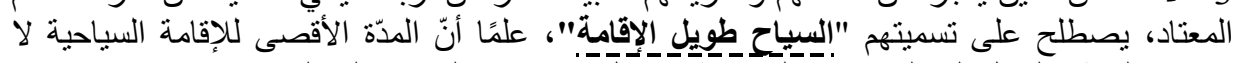

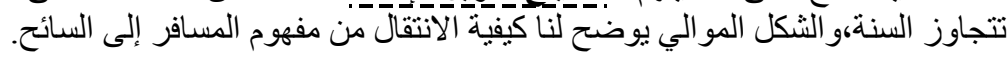




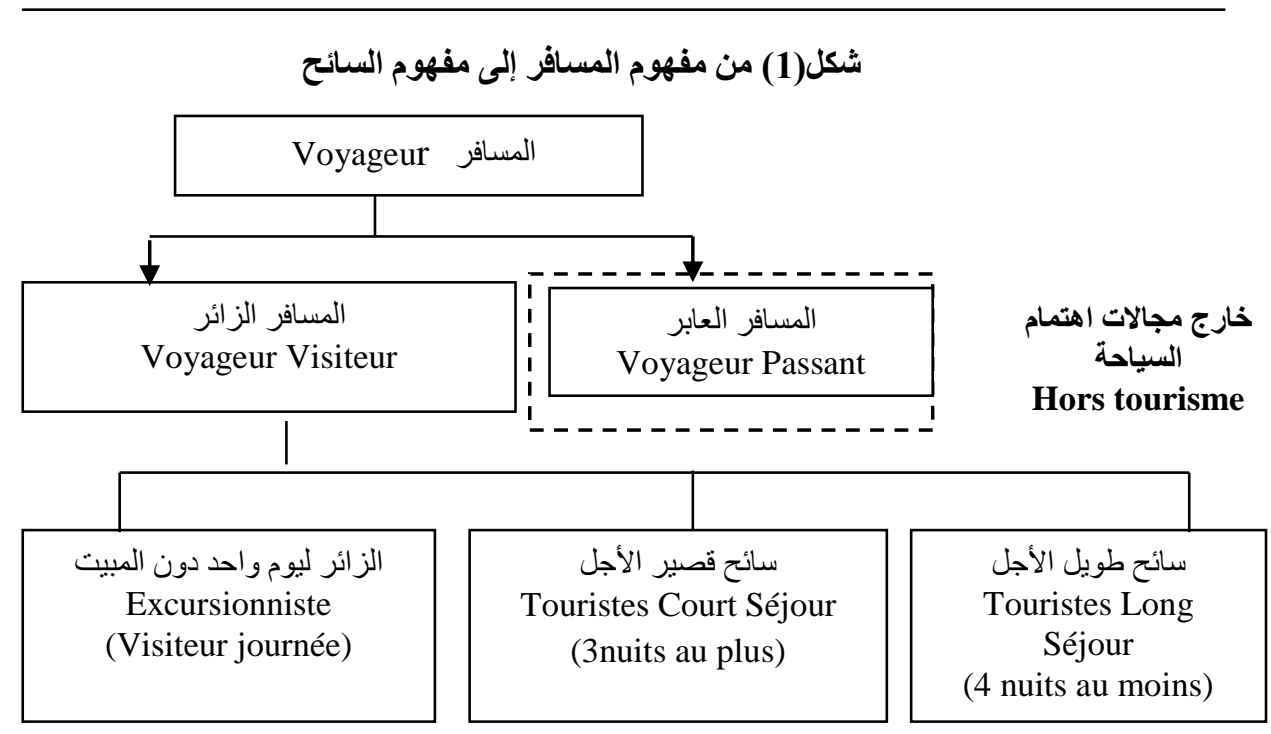

Source: Jean Pierre Lozato-Giotart, Michel Balfet, Management du tourisme: territoires, systèmes de production et stratégies, $2^{\text {ème }}$ édition, édition Pearson, Paris, 2014, P. 6.

وتقدم المنظمة العالمية للسباحة سنويًا عبر تقاريرها إحصائيات عن السباحة للبلدان المنخرطة فيها

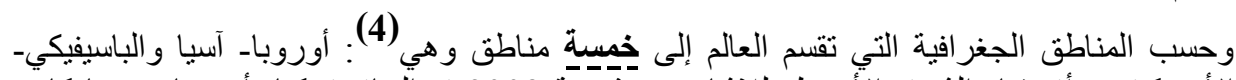

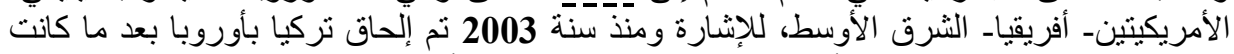

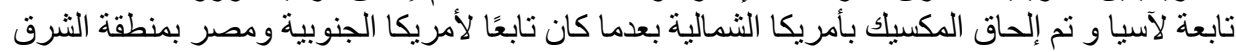

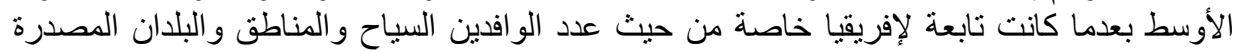

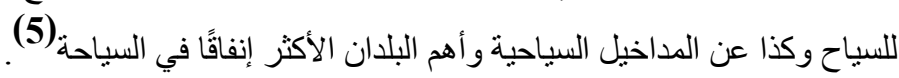

2. 2. أسباب تنقلات وزيارات السائح

حسب المنظمة العالمية للسياحة World Tourism Orgaization (UNWTO) W. (Wكن لنا

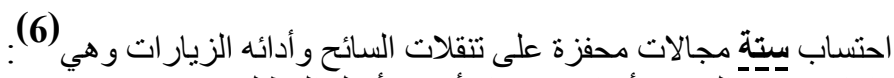

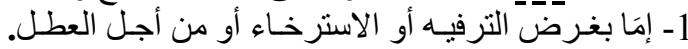

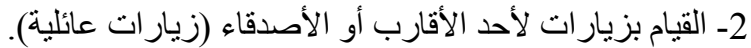

3- القيام بزيار ات من أجل العلاج الطبي و الصحة (الاستحمام الطبي، الذلك الطبي (Thalassothérapie)

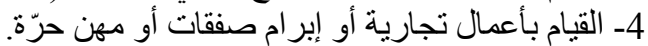

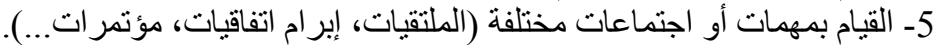
6- أسباب أخرى: كالزيارات الدينية، التظاهر ات الرياضية، الأسفار الددرسية.

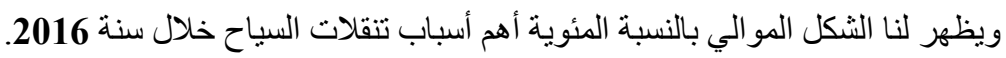


شكل (2) أسباب تنقلات وزيارات السياح خلال سنة 2016

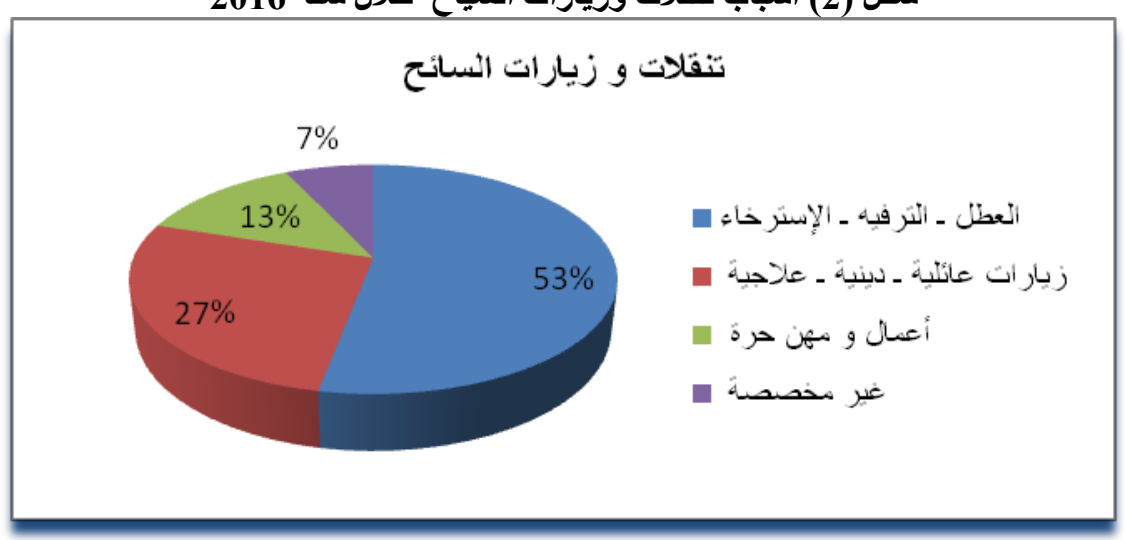

Source: World Tourism Organization (UNWTO), July, 2017.

وممّا لاثكك فيه فإنَّ القيام بالسياحة مرتبط بكل من إلـخلِل إلمتئح الذي تظهر الدراسة أنه كلما زاد بوحدة

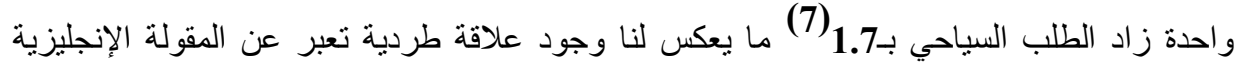
"man with money can go every where, without stay at home"

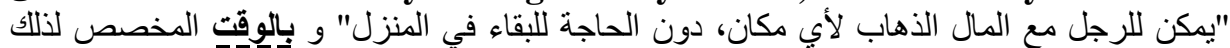

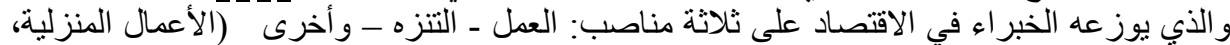
تدريس الأطفال، وقت النوم...) وهو ما يظهره الثكل الآتي:

شكل رقم (3) الوقت المخصص للسياحة

Temps disponible

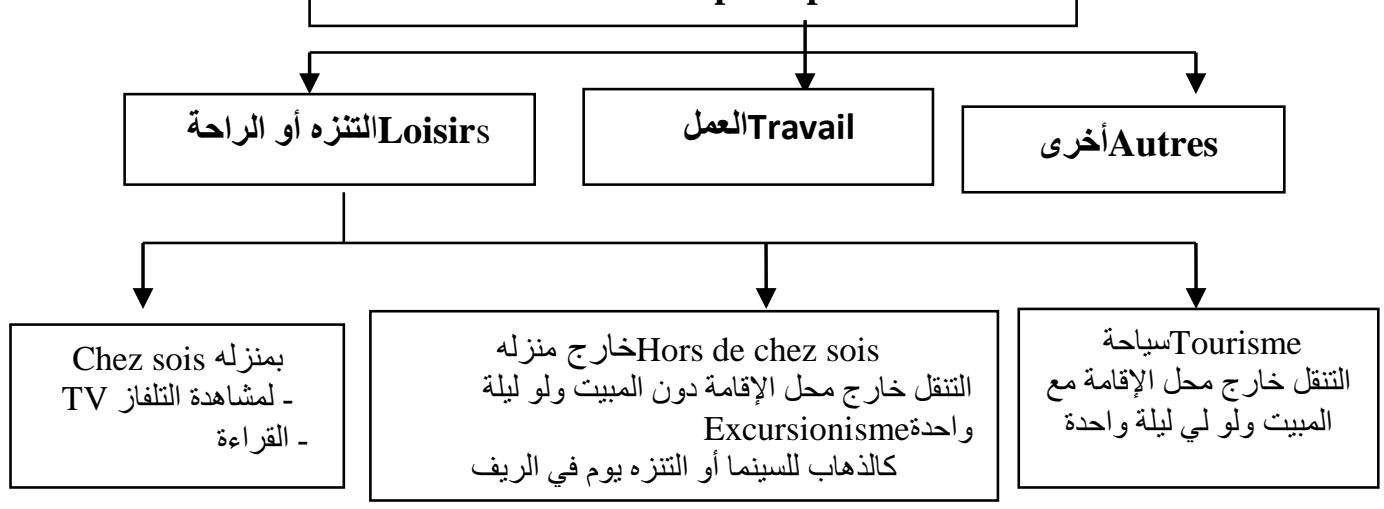

Source: Laurent Botti, Nicolas Pepoch, Bernardin Solon Andrasana, Economie du Tourisme, édition Dunod, Paris, 2013, P. 23. 
3. أهمية وتطور السياحة عالميًا

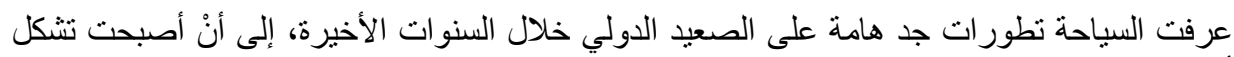

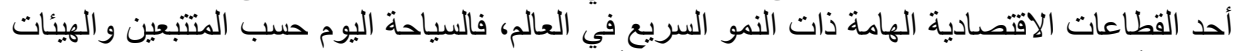

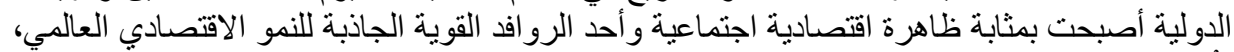

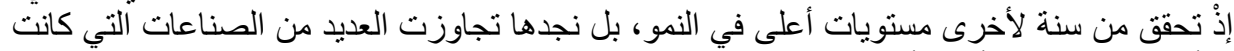

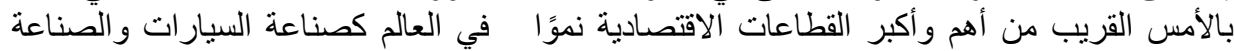

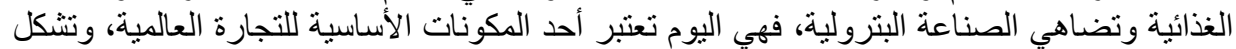

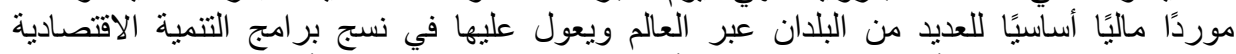

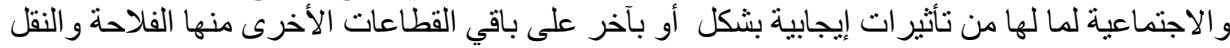

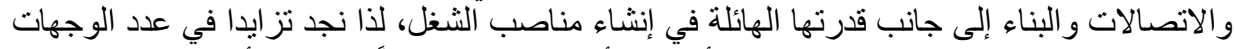

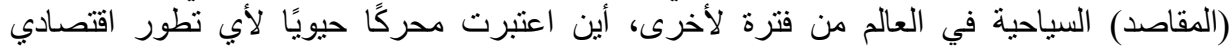

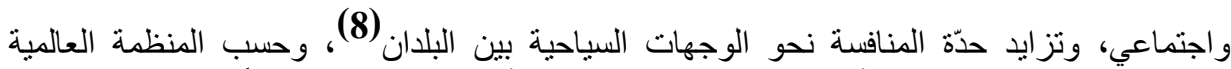

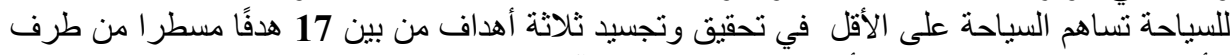

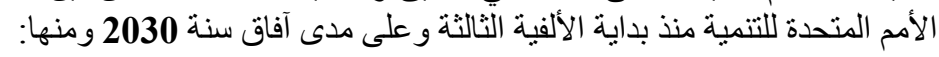

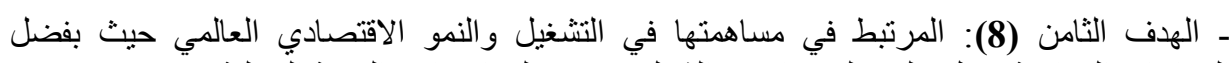

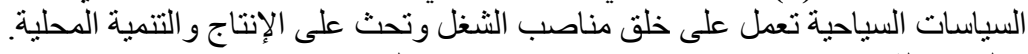

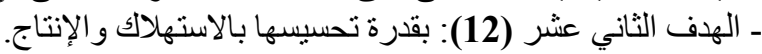
ـ ـ الهدف الرابع عشر (14): المرتبط بترشيد المياه وترشيد استهلاك ثروات الات البحار.

(9)

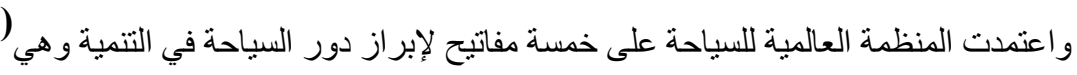

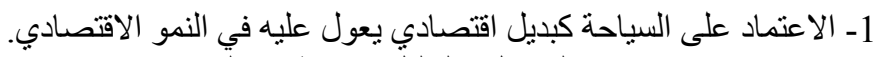

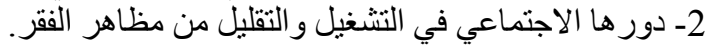

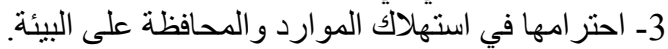
4- دور ها في ألتنوع و الاحتكاك الثنافي بين الثنعوب. 5- دور ها في استتباب الأمن و السلام العالمي.

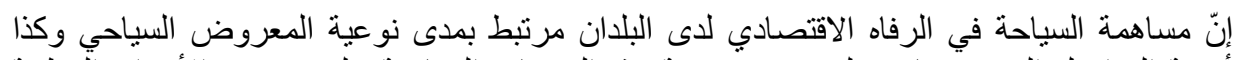

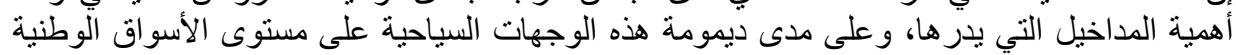
و الدولية، وحسب إحصائيات المنظمة العالمية للسياحة لسنة 2017 نمثل السياحة:

10\% من الناتج الداخلي الخام العالمي (PIB) و $\frac{1}{10}$ من مناصب الثغل المستحدثة ور اءها السياحة.

$$
\text { و تنساهم بمقدار } 1400 \text { مليار دو لار أمريكي (\$) من الصادرات العالمية. }
$$

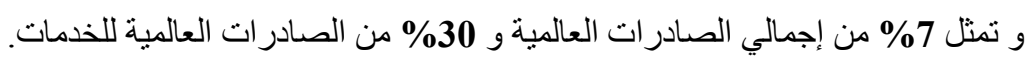

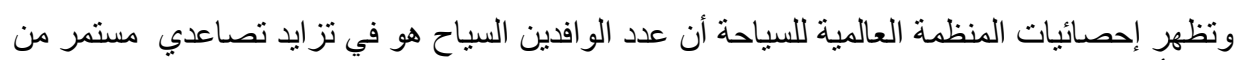
سنة لأخرى كما يظهره الثكل المو الي. 
في ظل إستراتيجية تطوير السياحة الجزائرية أثر النشاط السياحي على النمو الاقتصادي

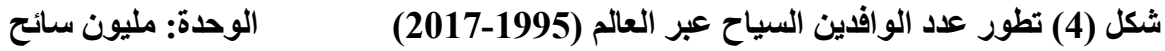

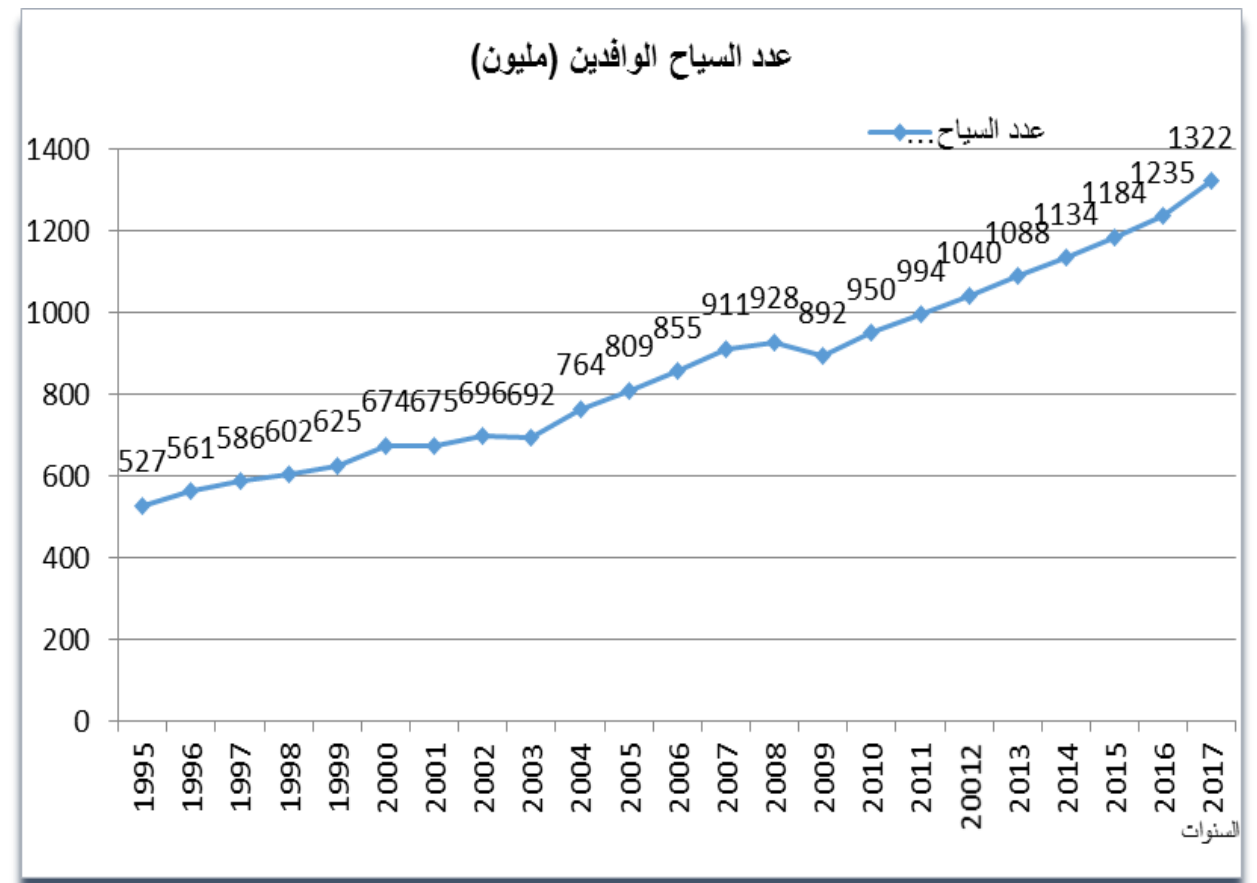

Source: Annual Report Tourisme 2015, 2016, 2017, UNWTO.

* ملاحظة: توقع المنظمة العالمية للسياحة (UNWTO) بلوغ عدد السيـاح الو افدين على المستوى عدد السياح

$$
\text { العالمي: }
$$

1.4 مليار سائح سنة 2020. و 1.8 مليار سائح سنة 2030. الوافدين

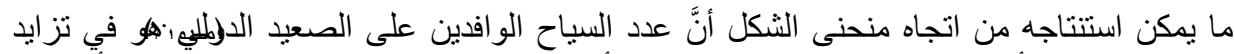

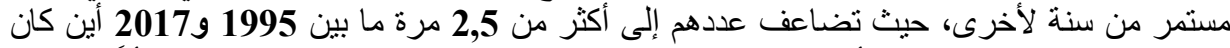

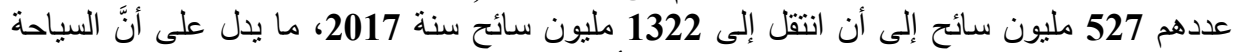

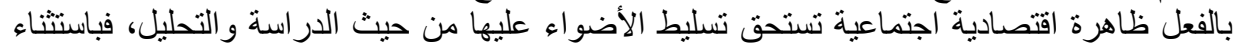

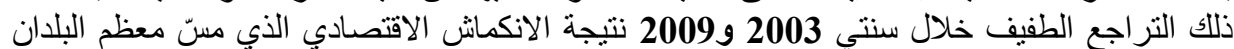

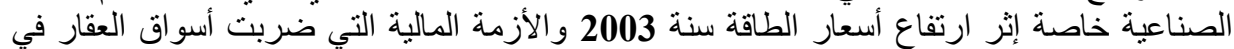

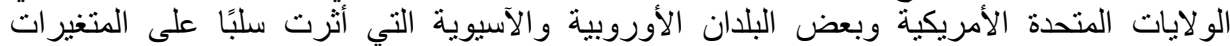

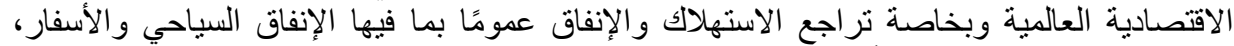

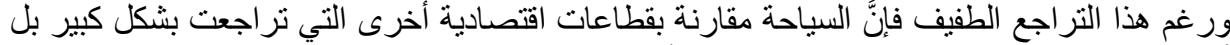

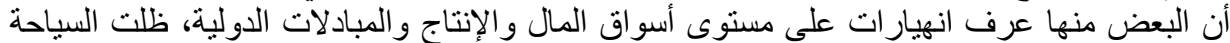

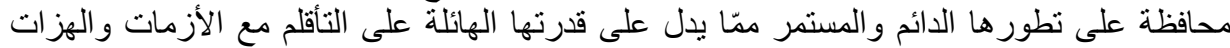




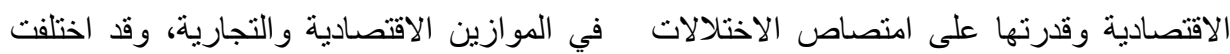

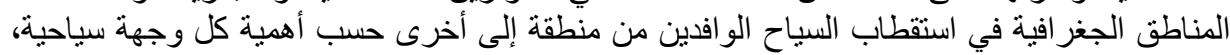
وهو ما بظهره الجدول الموالي في توزيع عدد السياح الوافين حسب الفي المناطق الجغر افية خلال سنة

جدول (1) توزيع عدد الوافدين السياح و المداخيل السياحية خلال سنة 2017 حسب المناطق

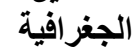

\begin{tabular}{|c|c|c|c|c|}
\hline النسبة المئوية & 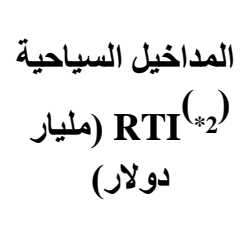 & النسبة المئوية من المياح & 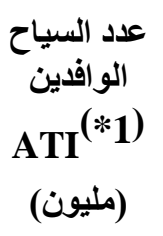 & الجغرافية \\
\hline$\% 36,64$ & 447 & $\% 50,76$ & 671 & أوروبا \\
\hline$\% 30,08$ & 367 & $\% 24,51$ & 324 & آسيا \\
\hline$\% 25,66$ & 313 & $\% 15,66$ & 207 & الأمريكيتين \\
\hline$\% 2,87$ & 35 & $\% 4,68$ & 62 & أفريقيا \\
\hline$\% 4,75$ & 58 & $\% 4,39$ & 58 & الثرق \\
\hline$\% 100$ & 1.220 & $\% 100$ & 1.322 & المجموع \\
\hline
\end{tabular}

Source: Organisation mondial du tourisme, Juillet 2017.

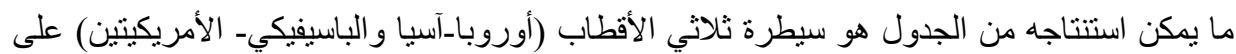

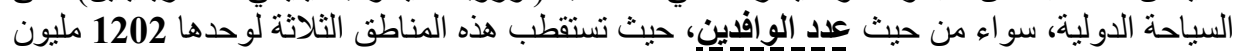

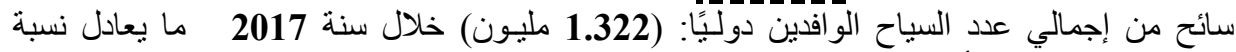

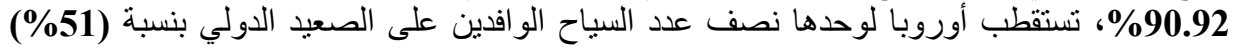

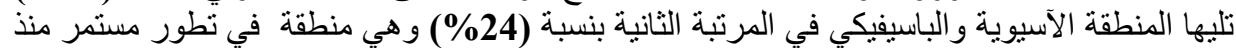

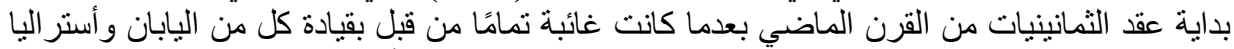

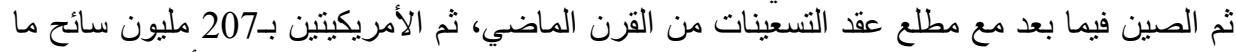

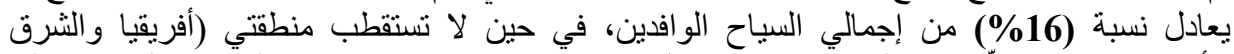
الأوسط) مجتمعة إلاّ 120 مليون سائح مأ يعادل نسبة 99 \%

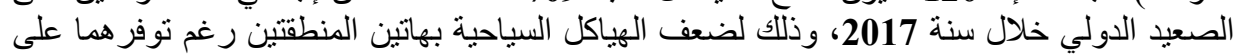
إمكانيات سياحية معتبرة كما يظهره لنا الثكل المو الي لئي 
في ظل إستراتيجية تطوير السياحة الجزائرية أثر النشاط السياحي على النمو الاقتصادي

شكل (5) حصة المناطق الجغرافية من الوافين السياح الدوليين خلال سنة 2017

التوزيع الجغر افي للسياح الوافين دوليا ـ الوحدة : مليون سائح

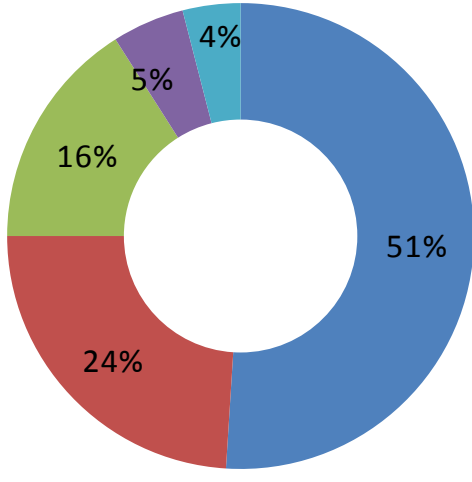

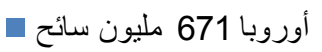

| آسيا و الباسيفيكي 324 مليون سائح

| الأمريكتين 207 مليون سائح

| أفريقا 62 مليون سائح

[ الثرق الأوسط 58 مليون سائح

\section{من إعداد الباحث اعتمادا على معطيات المنظمة العالمية للسياحة}

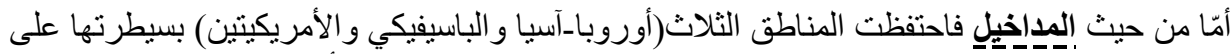

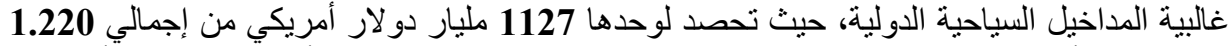

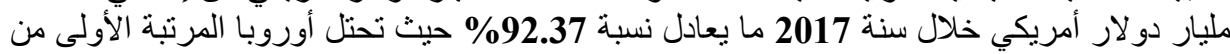

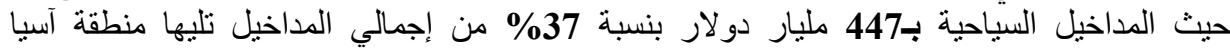

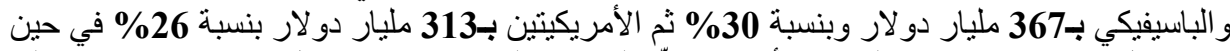

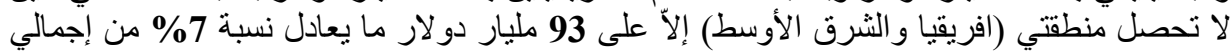
المداخيل السياحية الدولية كما يظهره لنا الثكل المو الأي. 
شكل (6) حصة المناطق الجغرافية من المداخيل السياحية الدولية خلال سنة 2017

التوزيع الجزرافي للمداخيل السباحية الدولية ـ الوحدة : مليار دولار أمريكي

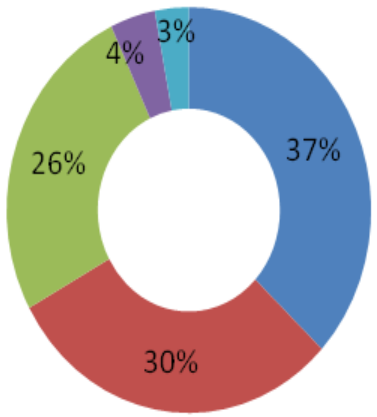

| أوروبا 447 ملبار دو لار

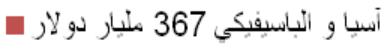

| الأمر بكتبن 313 نلبار دو لار

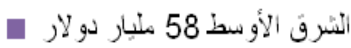

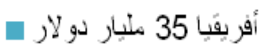

من إعداد الباحث اعتمادا على معطيات المنظمة العالمية للسياحة

ونسجل هنا بقاء منطقة البحر المتوسط في إلمِيِتية الأولِيلي عالميًا كقوة جذب سياحية عالمية لما تعرضه

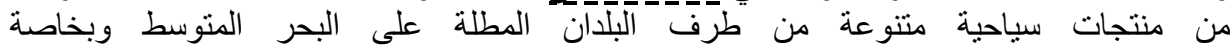

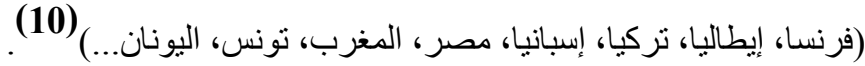

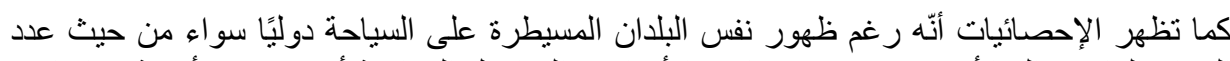
السياح الو افدين إلبها أو من حيث حصنها من الأرباح و الدداخيل السياحية أو من حيث الهيأ أهية نفقاتها في

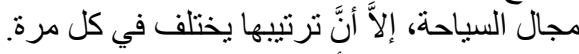
شكل (7) أهم البلان للوجهات السياحية العالمية خلال سنة: 2015 (مليون سائح)

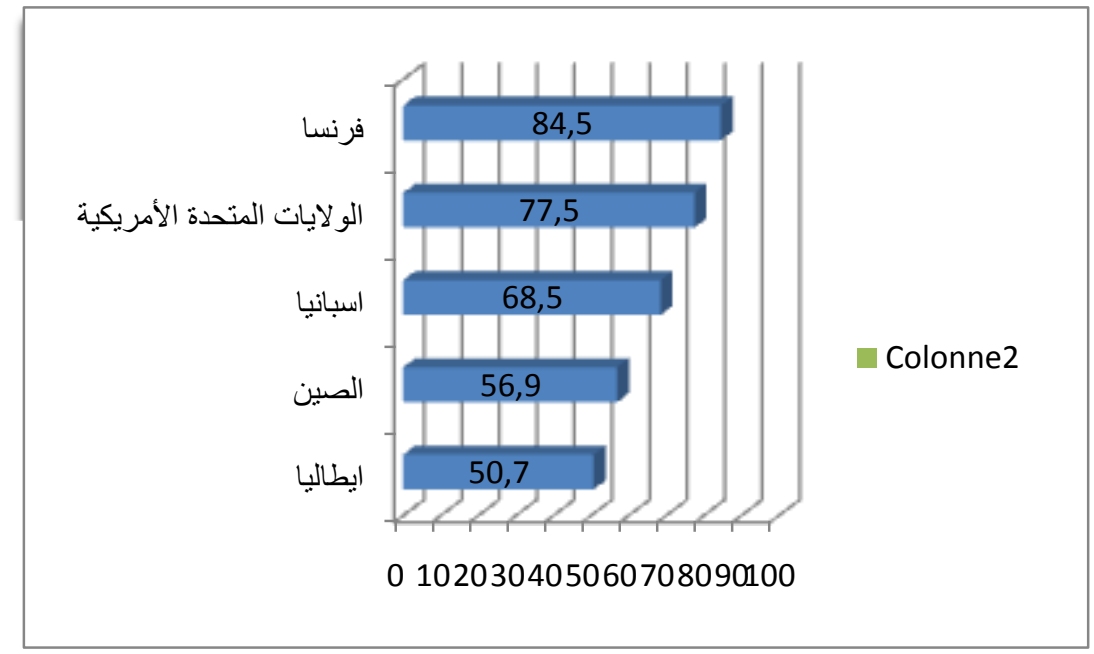


Source: Annual Report tourisme 2016, UNWTO, P. 13.

يتضح من الثكل رقم 7 احتلال فرنسا الريادة من بين أكبر خمس بلدان من حيث عدد السياح الو افدين

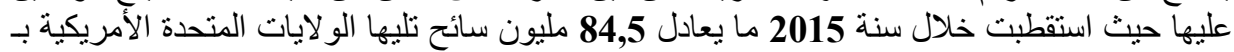

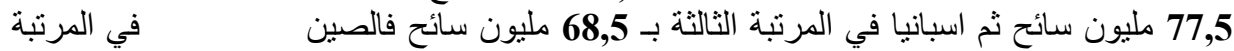

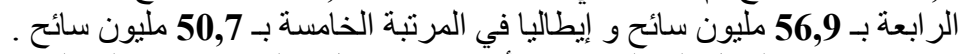
في حين يظهر الثنكل الموالي ترتيب أكبر خمس دول التربة عالميا سيطرة على المداخيل السياحية خلال سنة

شكل (8) أهم البلان من حيث المداخيل السياحية خلال سنة : 2016 (مليار دولار أمريكي)

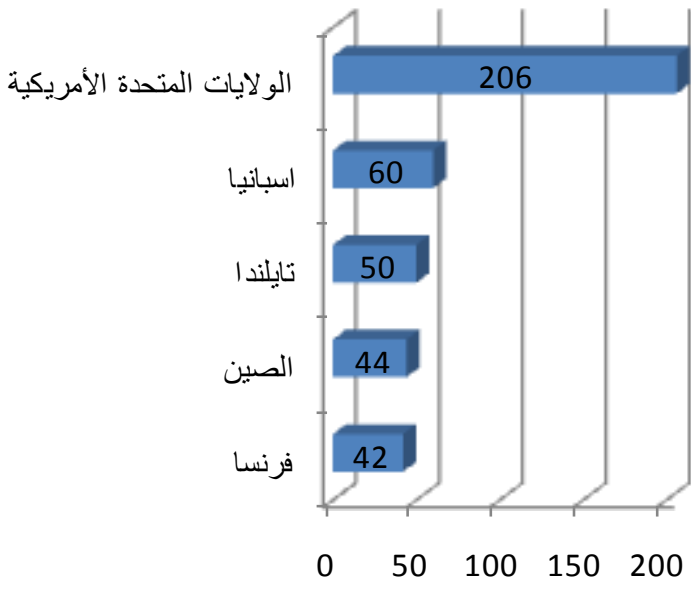

المداخيل السياحية (مليار

دو لار)

Source: Organisation mondial du tourisme UNTWO, Juillet 2017.

حيث يتضح مدى سبطرة الو لايات المتحدة الأمريكية على حصة كبيرة من المداخيل السياحية حيث تحتل

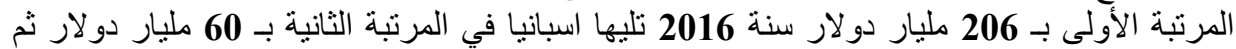

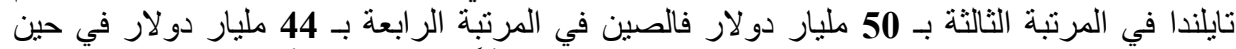

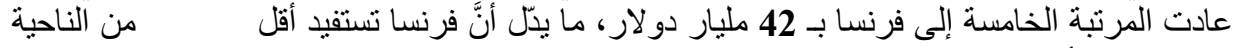

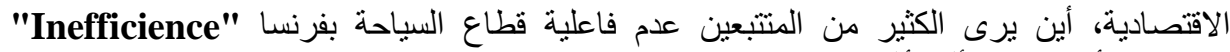

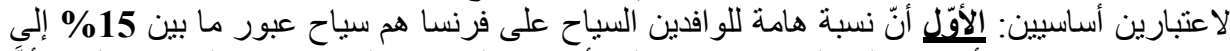

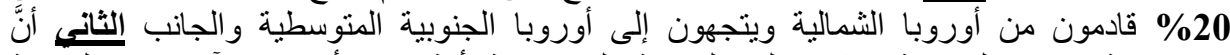

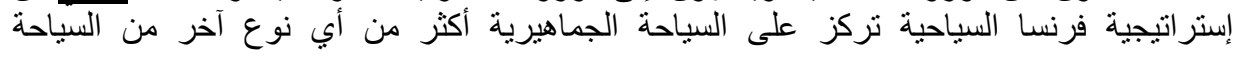
"(11)"Tourisme de Masse"

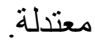

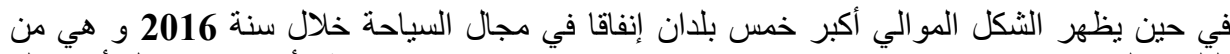

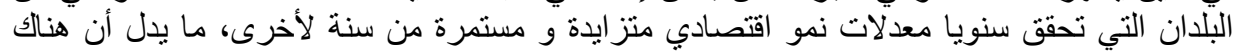


علاقة وطيدة بين تطور ات الإنفاق السياحي نتيجة زيادة المداخيل و تحسن مستوى المعيثة في البلدان

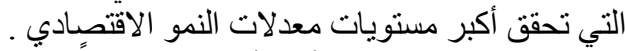
شكل (9) أكبر أهم البدان إنفاقًا في السياحة الدولية خلال سنة : 2016

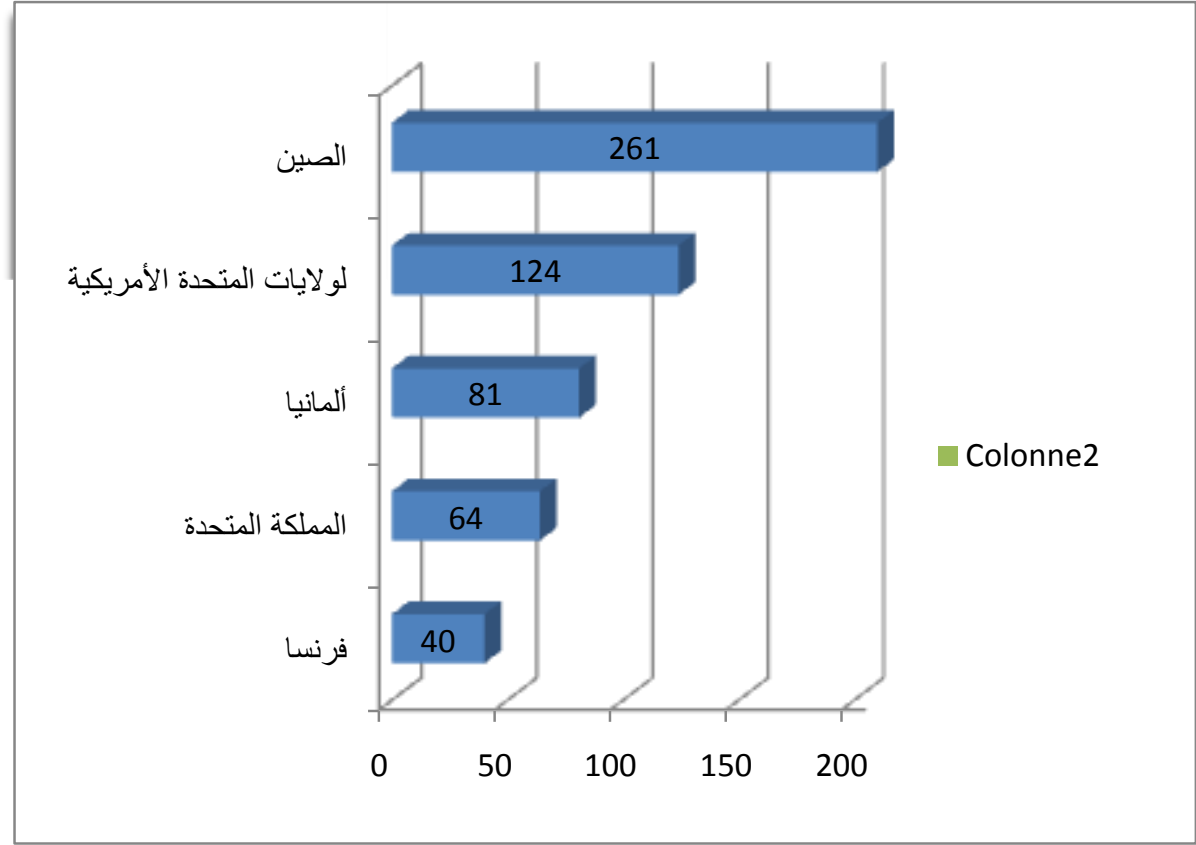

Source: Organisation mondial du tourisme UNTWO, Juillet 2017.

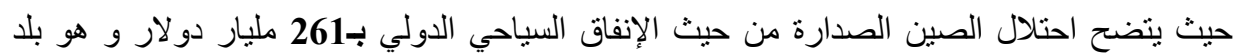

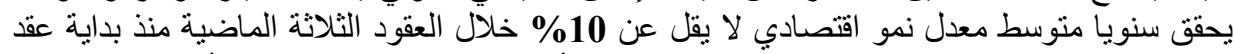

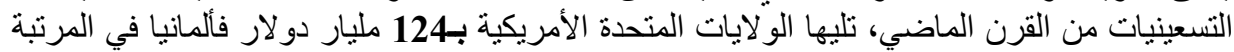

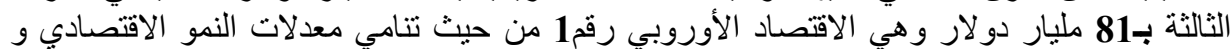

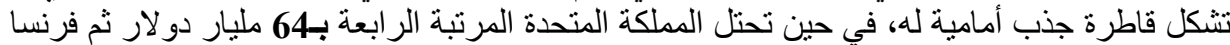

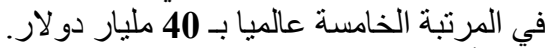

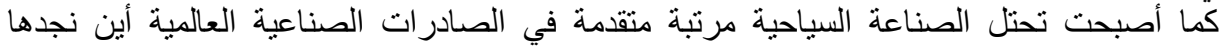

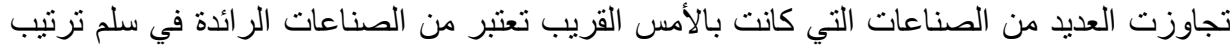
الصناعات العالية، و هو ما يظهره لنا الجدول الموالي التي: 
في ظل إستراتيجية تطوير السياحة الجزائرية أثر النشاط السياحي على النمو الاقتصادي

جدول (2) ترتيب حصة الصادرات الصناعية العالمية حسب الأنواع لسنة 2017 الوحدة: مليار دولار أمريكي

\begin{tabular}{|c|c|c|}
\hline مبلغ حجم الأعمال & نوع الصناعة & 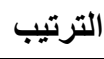 \\
\hline 1.857 & الصناعة الكيماوية & 1 \\
\hline 1.845 & الصناعة البترولية & 2 \\
\hline 1.413 & السياحة الدولية & 3 \\
\hline 1.334 & الصناعة الميكانيكية (صناعة السيارات) & 4 \\
\hline 1.328 & الصناعة الغذائية & 5 \\
\hline
\end{tabular}

Source: World Tourism Orgaization (UNWTO), July 2017.

ما يمكن ملاحظته من الجدول المكانة المرموقة التي أصبحت تحتلها الصناعة السياحية الدولية إذّ جاءت

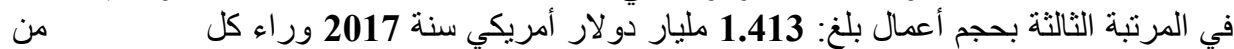

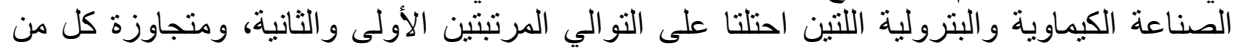

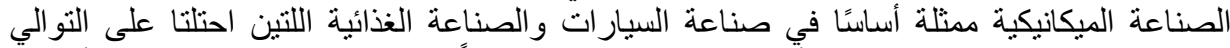

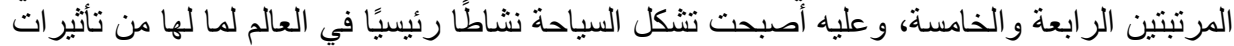

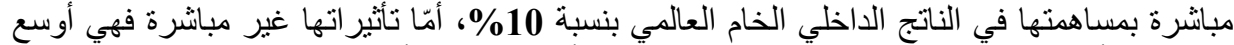

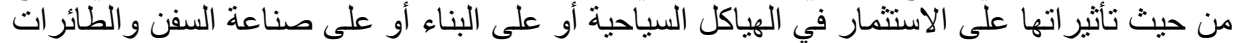

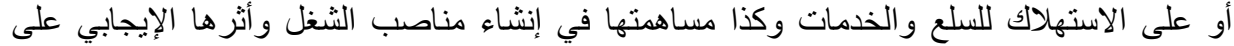

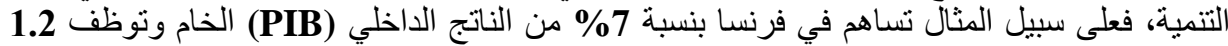
مليون منصب عمل مبانشر.

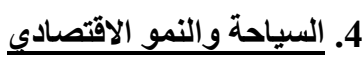

غالبًا ما يتم طرح إنثكالية تفسير العلاقة القائمة بين السياحة والنشاط الاقتصادي من خلال تحليل

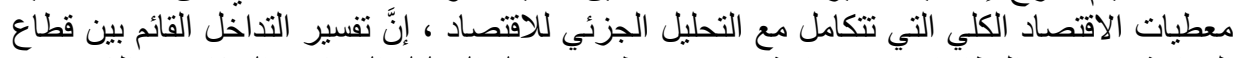

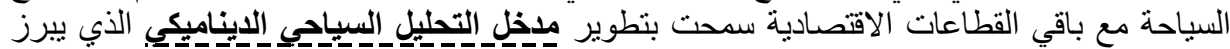

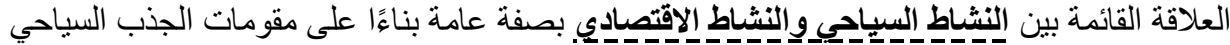

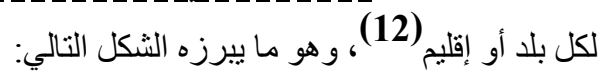

شكل (10) التداخلات الكلية بين قطاع السياحة والنثاط الاقتصادي العام

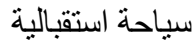

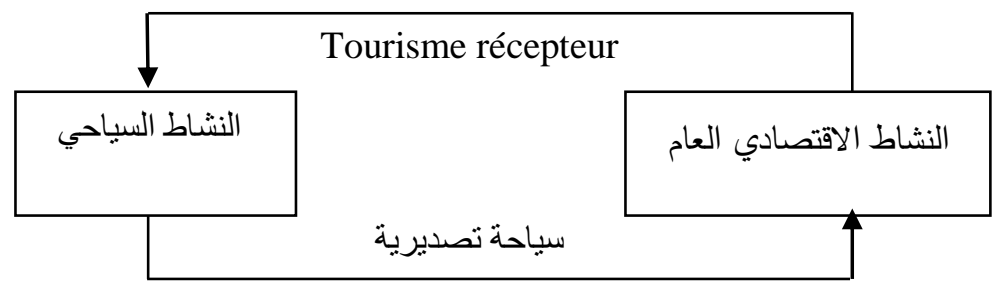

Tourisme émetteur 
Source: Jean-Louis Caccomo, Fondements d'économie du Tourisme, 1 ère édition, édition, De Boeck, Bruxelles, 2007, P. 154.

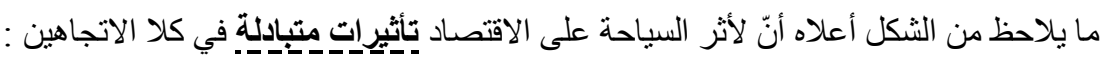

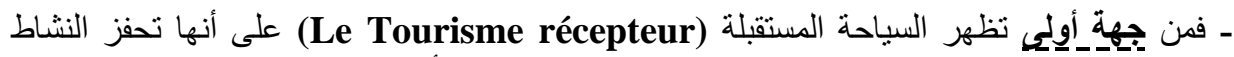

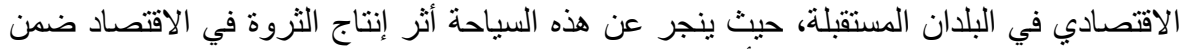
الائرة الاقتصادية، فهي تؤدي إلى تأثير ات إيجابية مضاعفة (Multiplicateurs)

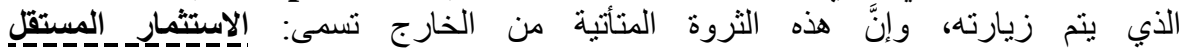
(Investissement autonome)

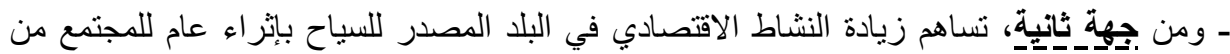

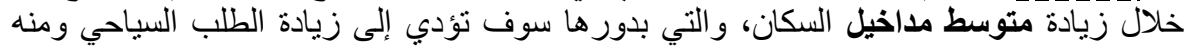

تعميم تصدير السياح.

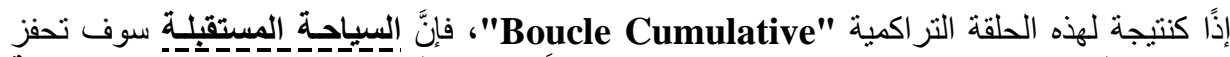

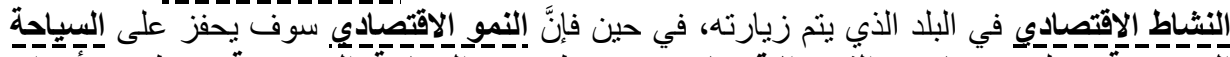

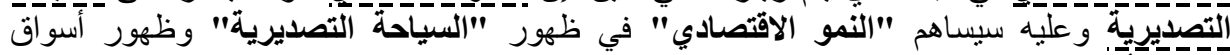

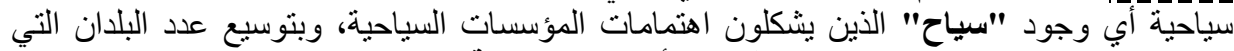

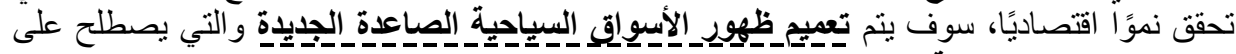

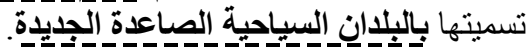

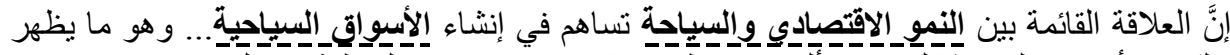

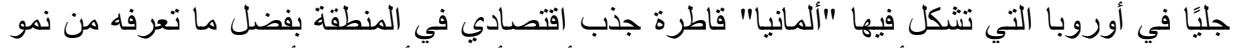

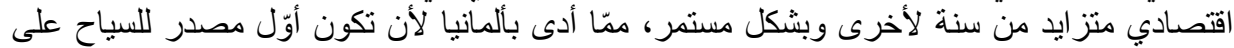

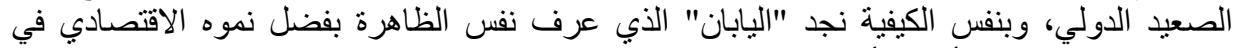

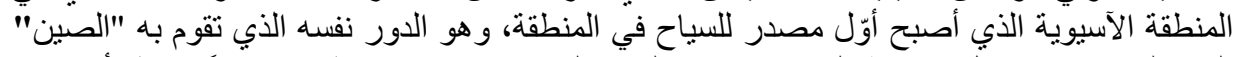

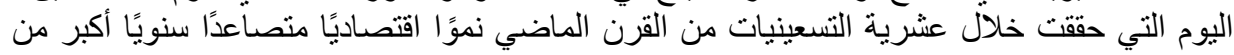

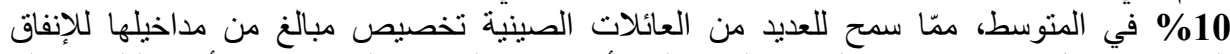

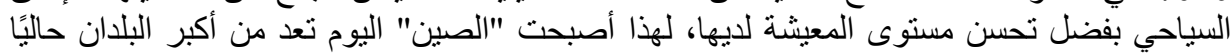
المصدرة للسياح بعد عملية الإقلاع التي عرفها القتصادها.

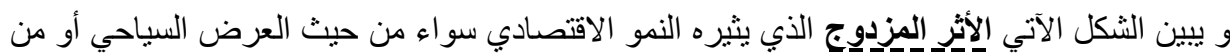

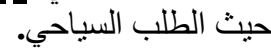
شكل (11) العلاقات القائمة بين العياحة والنمو الاقتصادي

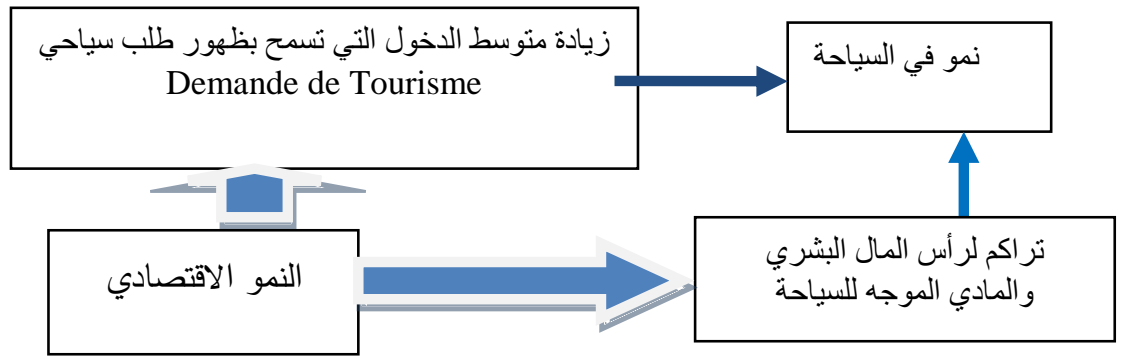

Source: Jean-Louis Caccomo, op-cit, P. 156. 


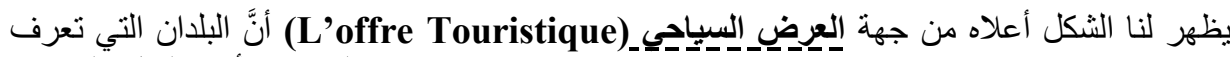

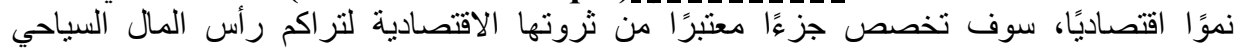
(المالي- البشري- و المادي) الذي يسمح بإنشاء نثاطات سياحية.

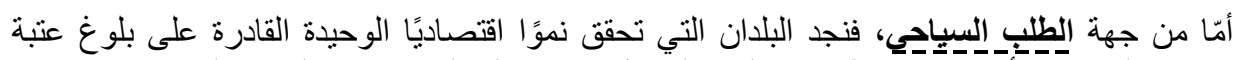

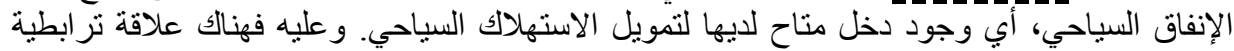

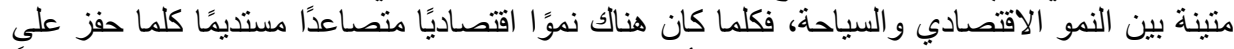

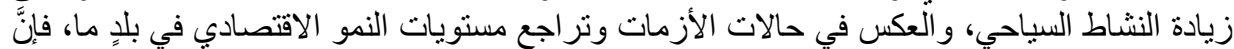

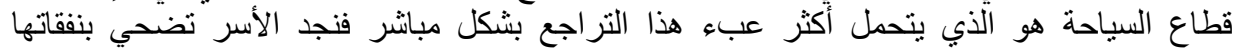

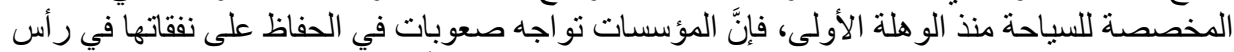

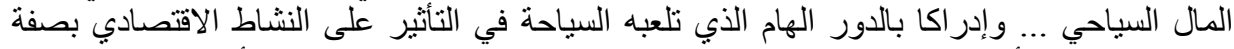

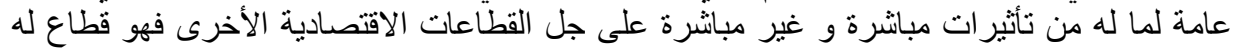

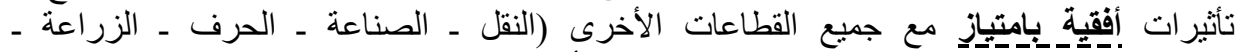

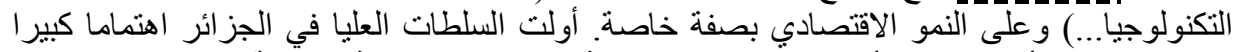

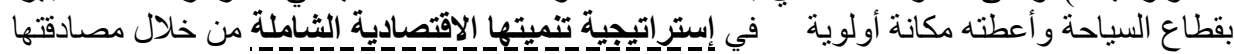

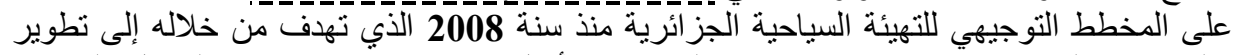

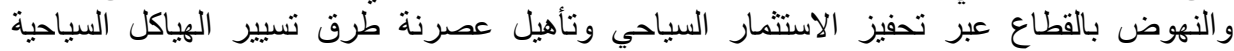

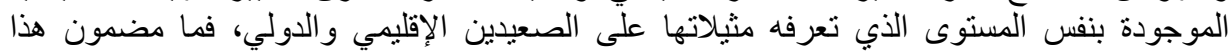

المخططو آليات عمله؟ المبن

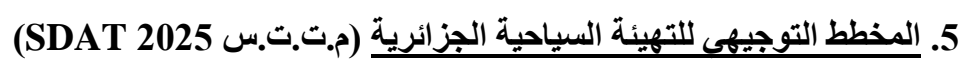

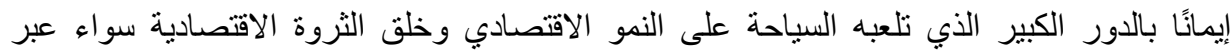

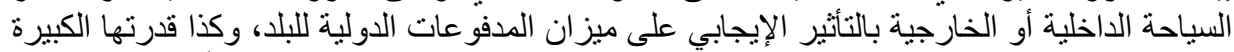

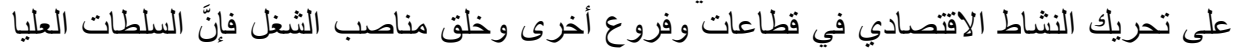
للجزائر وضعت إستر اتيجية شاملة لنطوير قطاع السياحة منذ سنة 2008 على مدار أفق 2025 تسمح

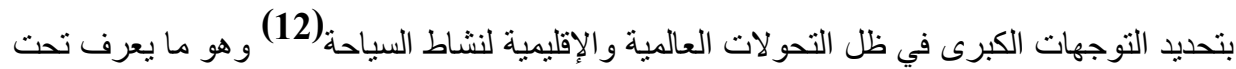

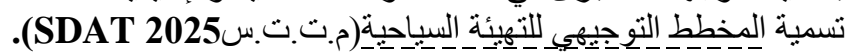
عبر ستة كتب متكاملة مع بعضها البعض قاربت 400 صفحة، أين قام الخبراء بـ: ـ ـتشيص عام لوضع السياحة بالجز ائر في الكتاب الأوّل.

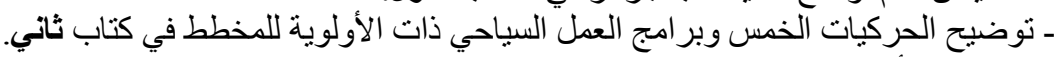

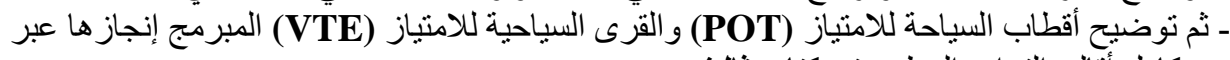

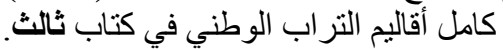

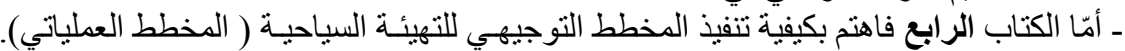

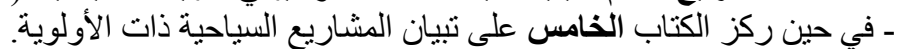
ــ أمّا الكتاب السادس فخصص لـابل لإعطاء خلاصة شاملة للمخطط التوجيهي للتهيئة السياحية.

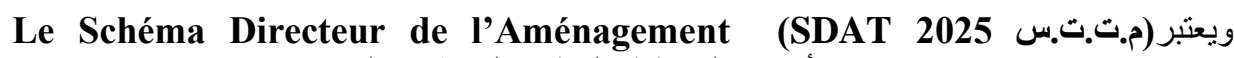

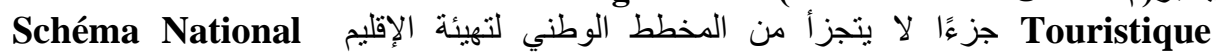
d'Aménagement du Territoire (SNAT) ديسمبر 2001 و02-101 بتاريخ 29 جوان 2010(14)، حيث بهدف هذا المخطط إلى نوزيع عادل 
اللسكان و النشاطات على كامل أقاليم التراب الوطني، و هذا من خلال إعادة تنظيم الأقاليم وتطوير أقطاب

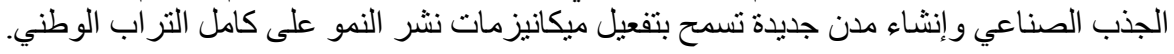

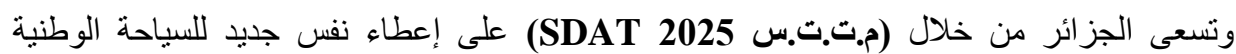

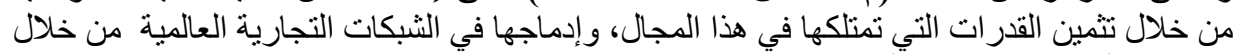

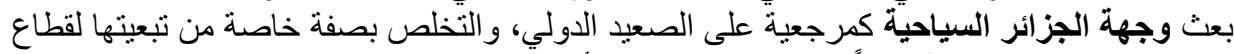
المحروقات باعتباره موردًا قابلاً للنضوب وتئة وتتحكم في أسعاره احتكار ات دولية.

$$
\text { وذلك عبر تحقيق الأهداف التالية(15): }
$$

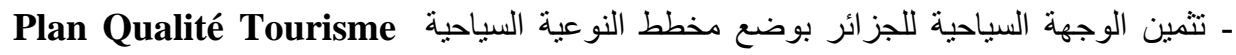

ـ ـ تطوير العرض السياحي عبر الاستثمار في أقطاب وقرى الامتياز السياحي. - وضع مخطط شر اكة بين القطاعين العام و الخاص من أجل تدعيم السلسلة السياحية.

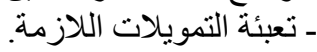

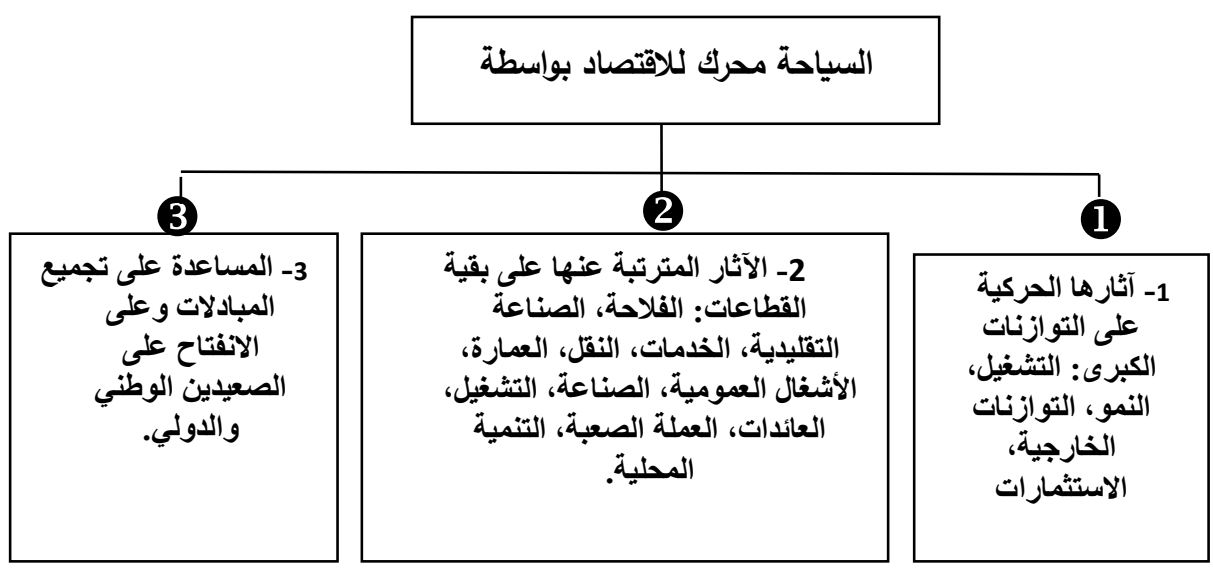

المصدر: وزارة تهيئة الإقليم والبيئة والسياحة، المخطط التوجيهي للتهيئة السياحية(م.ت.س.س 800 (SDAT 2025

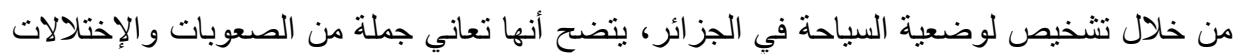

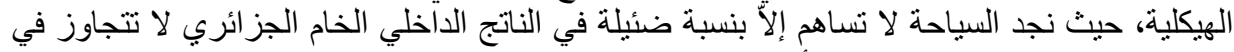

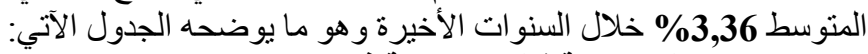

جدول (3) تطور حصة قطاع السياحة في الناتج الداخلي الخام الجزائري للفترة (2011-2016) الوحدة: (\%)

\begin{tabular}{|c|c|c|c|c|c|c|}
\hline $\mathbf{2 0 1 6}$ & $\mathbf{2 0 1 5}$ & $\mathbf{2 0 1 4}$ & $\mathbf{2 0 1 3}$ & $\mathbf{2 0 1 2}$ & $\mathbf{2 0 1 1}$ & السنة \\
\hline 1.3 & 1.3 & 1.9 & 4.2 & 4.9 & 6.6 & $\%$ \\
\hline
\end{tabular}

Source: Office National des Statistique (ONS) , 2017 
في ظل إستراتيجية تطوير السياحة الجزائرية أثر النشاط السياحي على النمو الاقتصادي

كما أنَّ مساهنتها في ميز ان المدفو عات الخاص بالأسفار و الخدمات تحقق عجزًا من سنة لأخرى و هو ما تظهره وضعية الميزان للفترة (2011-2007).

جدول (4) تطور ميزان المدفوعات أسفار وخدمات للفترة: (2011-2007) الوحدة: مليون دولار (\$) أمريكي

\begin{tabular}{|c|c|c|c|c|c|}
\hline 2011 & 2010 & 2009 & 2008 & 2007 & لـلينة \\
\hline 3909.8 & 3613.0 & 2986.6 & 3487.1 & 2837.7 & إيرادات \\
\hline 11972.2 & 11856.1 & 11681.1 & 11075.9 & 6930.4 & نققات \\
\hline 8062.4 - & 8243.1 - & 8694.5 - & 7588.8 & 4092.7 - & رصيد \\
\hline 208.3 & 219.1 & 266.4 & 324.5 & 218.9 & إيرادات \\
\hline 501.7 & 574.3 & 456.6 & 468.6 & 376.7 & نفقات \\
\hline $293.3-$ & $355.2-$ & $190.2-$ & 144.1 - & $157.8-$ & رصيد \\
\hline
\end{tabular}

Source: Office National des Statistique (ONS).

أمّا من حيث طاقات الجز ائر الاستقبالية خاصة في مجال الفنادق فهي جد محدودة إذّ لم تتجاوز مجتمعة بمختلف أنو اعها 1184 فندق سنة 2011، و هو ما يظهره لنا الجدول الآتي:

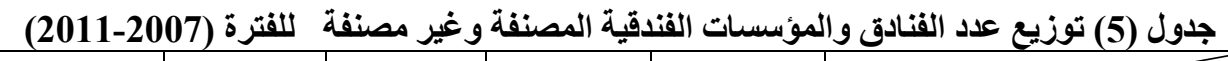

\begin{tabular}{|c|c|c|c|c|c|}
\hline 2011 & 2010 & 2009 & 2008 & 2007 & نوع الفندق ـ اللينة \\
\hline 13 & 13 & 13 & 13 & 13 & خمسة نجوم (*****) \\
\hline 64 & 39 & 57 & 53 & 54 & أربعة نجوم (****) \\
\hline 60 & 77 & 152 & 142 & 145 & ثلاثة نجوم (***) \\
\hline 74 & 72 & 148 & 160 & 157 & نجمتين (**) \\
\hline 58 & 58 & 101 & 99 & 97 & نجمة واحدة (*) \\
\hline 915 & 893 & 680 & 680 & 674 & فنادق خارج التصنيف \\
\hline 1184 & 1152 & 1151 & 1147 & 1140 & المجموع \\
\hline
\end{tabular}

Source: ONS.

أمّا من حيث عدد الأسرة فلم تتجاوز مجتمعة: 92737 سرير عند سنة 2011 كما تظهره معطيات

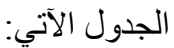




\begin{tabular}{|c|c|c|c|c|c|}
\hline 2011 & 2010 & 2009 & 2008 & 2007 & \\
\hline 4948 & 4948 & 5455 & 5455 & 5455 & خمسة نجوم \\
\hline 3750 & 3560 & 3950 & 3743 & 3743 & أربعة نجوم (****) \\
\hline 13180 & 13090 & 11700 & 11601 & 11225 & ثلاثة نجوم (***) \\
\hline 8070 & 8070 & 6044 & 5843 & 5843 & نجمتين (**) \\
\hline 3804 & 3804 & 2378 & 2378 & 2378 & نجمة واحدة (*) \\
\hline 58985 & 58905 & 56856 & 56856 & 56356 & فنادق خارج التصنيف \\
\hline 92737 & 92377 & 86383 & 85876 & 85000 & المجموع \\
\hline
\end{tabular}

Source: ONS, Bulletin $\mathrm{N}^{\circ} \mathbf{7 4 0 ,}$ P. 1.

ورغم أنَّ منطقة حوض البحر الأبيض الكنوسط الوجهة السياحية الرئيسية العالمية بنسبة 34\% من

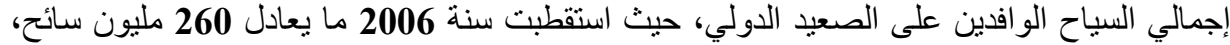

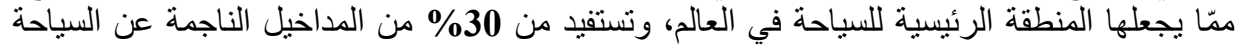

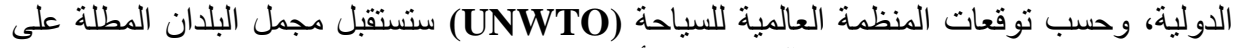

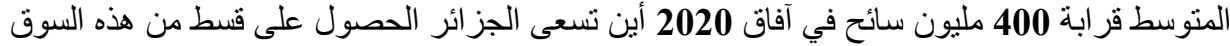

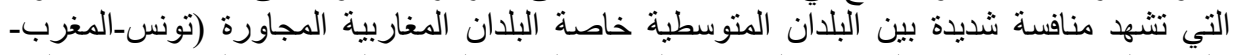

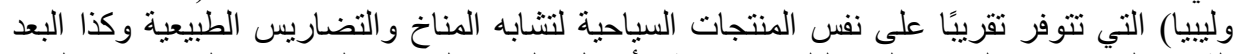

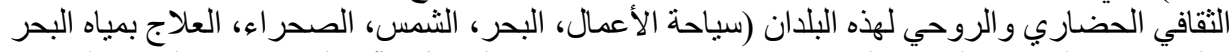

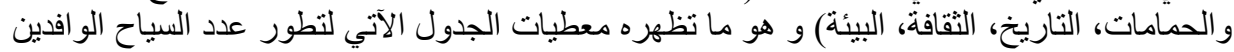
في المنطقة المغاربية ما بين (1995-2010).

جلول (7) تطور عدد السياح الوافين للمنطقة المغاربية ـ الفترة (1995-2010) الوحدة: مليون سائح

\begin{tabular}{|c|c|c|c|c|}
\hline 2010 & 2005 & 2000 & 1995 & \\
\hline 10.000 .000 & 6.378 .000 & 5.058 .000 & 4.120 .000 & تونس \\
\hline 10.000 .000 & 5.843 .000 & 4.278 .000 & 2.602 .000 & المغرب \\
\hline 2.500 .000 & 1.443 .000 & 866.000 & 519.600 & الجزائر \\
\hline
\end{tabular}


في ظل إستراتيجية تطوير السياحة الجزائرية أثر النثاط السياحي على النمو الاقتصادي

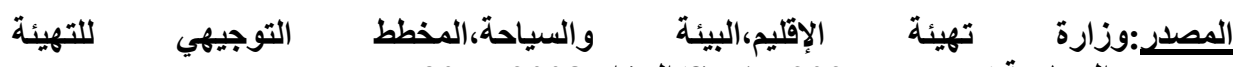
السياحية(م.ت.ت.س.

حيث يتضح أنَّ حصة الجزائر من عدد السياح الو افدين إلى المنطقة المغاربية هي الأضعف، إذْ لا تمثل

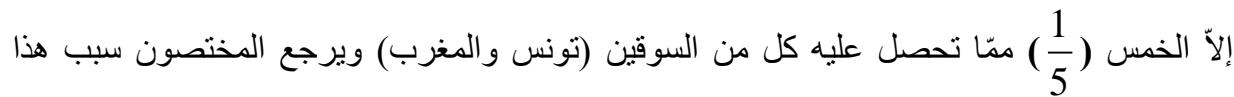
الضعف خاصة لغياب الاستثمار في التجهيزات السياحية التي عرفت توقف شبه كلي لجميع النشاطات

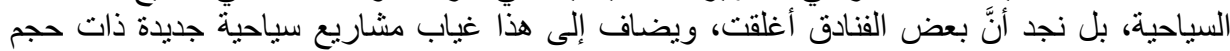

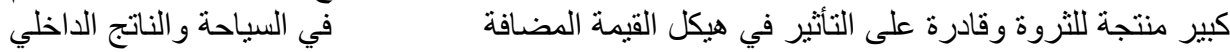

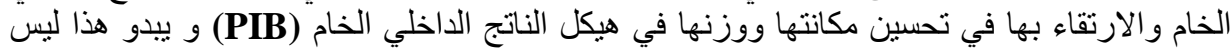

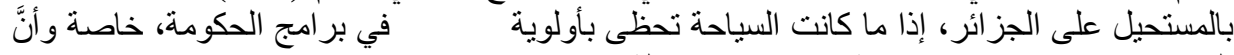

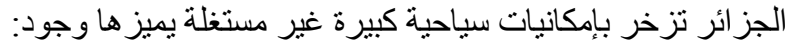

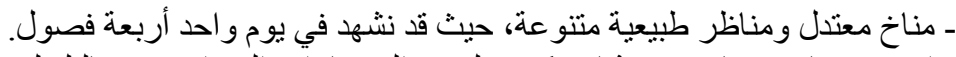

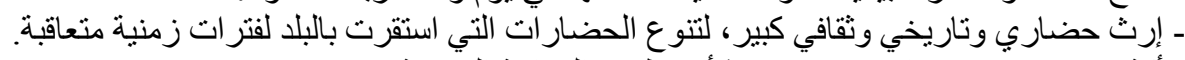

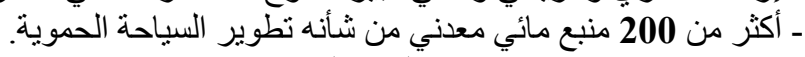
ـ - سياحة صحر اوية واعدة ذات ذات طلب دولي.

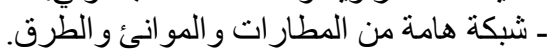

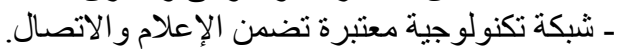
ـ القرب من أهم الأسواق الموفدة للسياح.

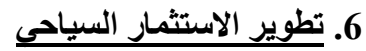
يرى الكثير من المختصين أنّه حتى تسنطيع الجزائر الاندمـاج في الأسـواق الجهويـة و الدولية للسياحة،

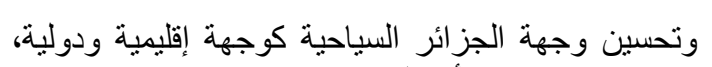
(16)

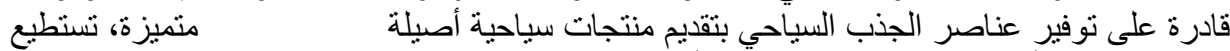

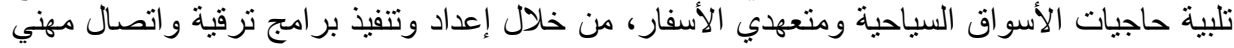
يتكيف مع خصوصيات كل سوق سياحي على حدى.

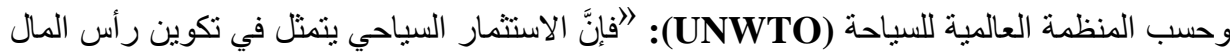
الخام السياحي، وذلك من خلال خاصة حيازة الموجودات الثابتة المتواجدة على الثي الإقليم الاقتصادي

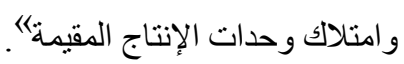

ويظهر الجدول الموالي: ترتيب النشاطات الإنتاجية لرأس المال السياحي.

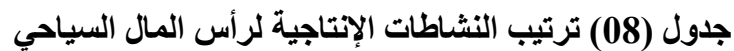

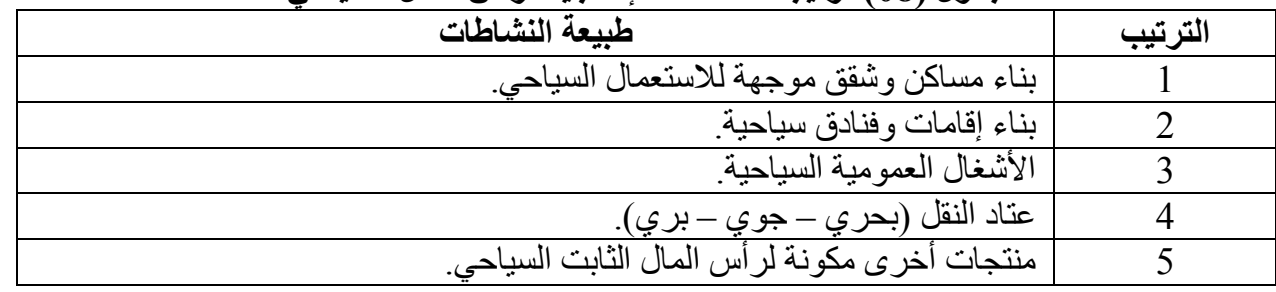

Source: Jean-Louis Caccomo, Fondements d'Economie du Tourisme,

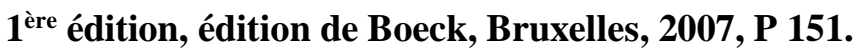


يتبين من الجدول أعلاه أنَّ رأس المال السياحي هو ناتج لعدد كبير من النشاطات المهيكلة التي تقام

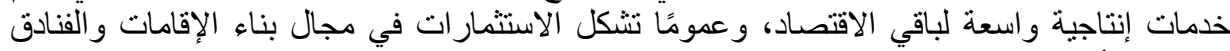

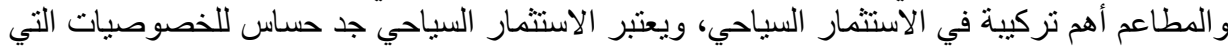
تميزه:

- فهو من جهة أولى يعتبر من الاستثمارات الصناعية الثقيلة (Industrie Lourde) ومردوديته

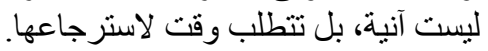
- ومن جهة أخرى نجد أن تمويلات قطاع السياحة كثيرة الكلفة.

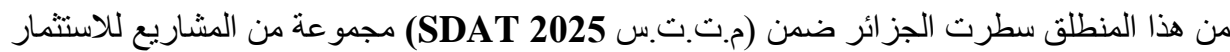
السياحي ذات الأولوية تدور حول:

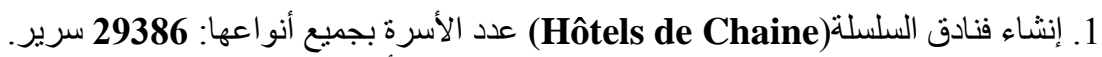

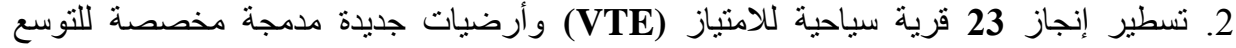

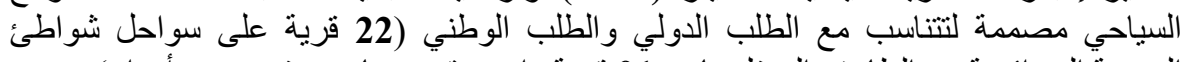

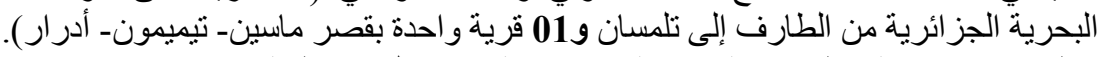

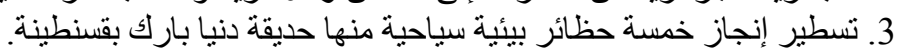

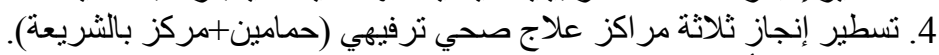

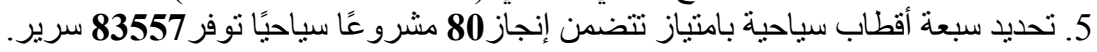

جدول (9) قدرات الإيواء المتوقعة للاستثمارات الفندقية والقرى العياحية الوحدة: عدد الأسرة

\begin{tabular}{|c|c|c|c|c|}
\hline إلأسلي عدة & للامتيّز (عديد القيادية & الفنادقات) (من جديع & القطب السياحي للامتياز & 里事 \\
\hline 49144 & سرير 11 قرية 39849 & 9295 & القطب السياحي (شمال وسط) & 32 \\
\hline 13343 & 3 قرية 7378 سرير & 5965 & القطب السياحي (شمال شرق) & 23 \\
\hline 16998 & سرير 4 قرية 6852 & 10146 & القطب السياحي (شمال غرب) & 18 \\
\hline 2184 & 1 قرية 92 سرير & 2092 & الواحات) السياحي (جنوب شرق & 04 \\
\hline 1513 & $\mathbf{0}$ & 1513 & 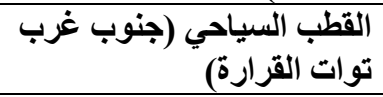 & 02 \\
\hline 150 & $\mathbf{0}$ & 150 & 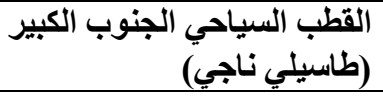 & 00 \\
\hline 225 & $\mathbf{0}$ & 225 & ـ ألظب السياحي الجنوب الكبير & 01 \\
\hline 83557 سرير & 19 قرية 54171 & 29386 & إجمالي الأسرة & 80 \\
\hline
\end{tabular}




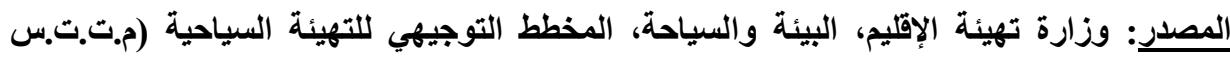

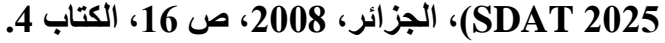

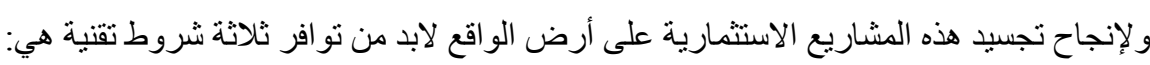

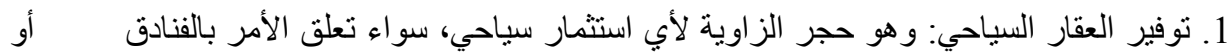

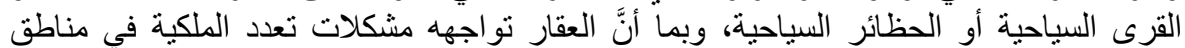

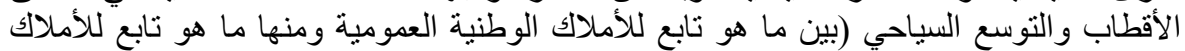

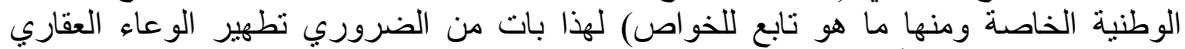

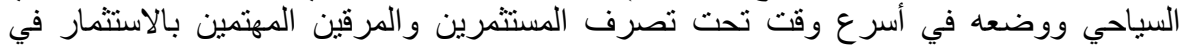
أقطاب السياحة للامتياز المقترحة.

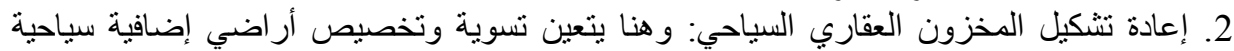

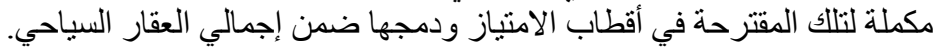

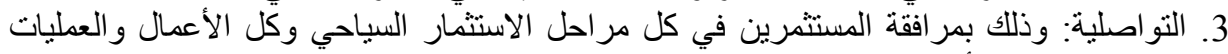

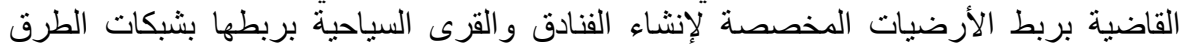
و المو اصلات وشبكات الاتصال و المنشآت القاعدية الضرورية و القيام بتسوية الأرضيات.

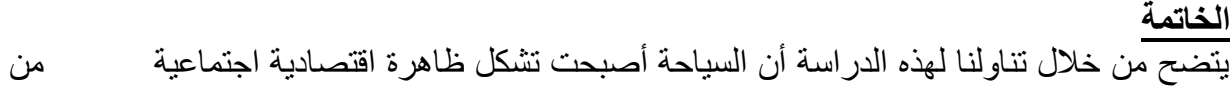

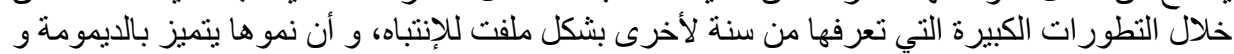

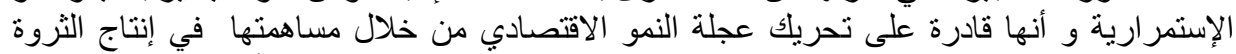

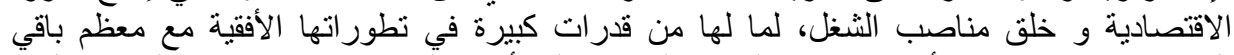

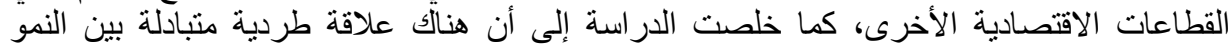

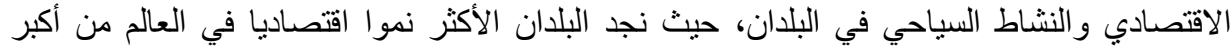

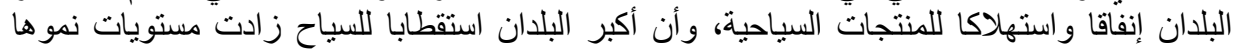

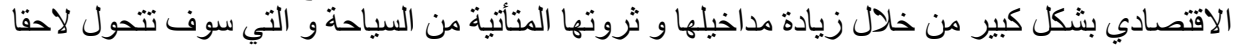

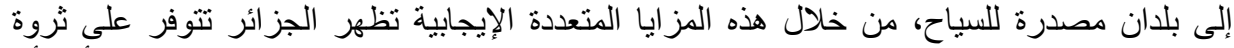

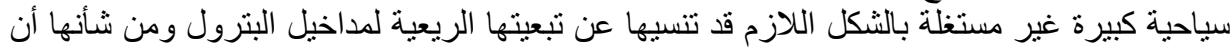

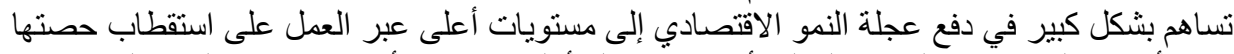

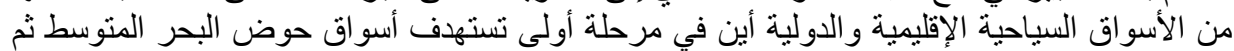

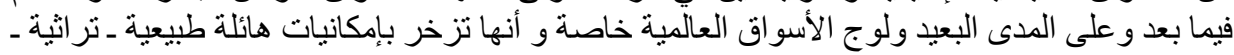

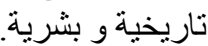
نتائج الاراسة: خلصئة خلصنا من هذه الدر اسة إلى جملة من النتائج أهمها:

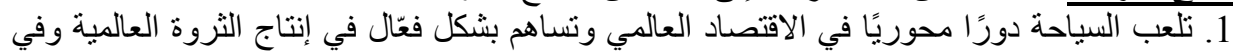

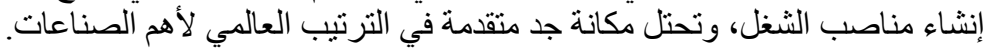

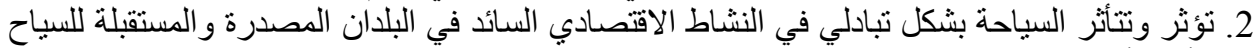
تأثنيرًا أفقيًا.

3. تعتمد كثبر من البلدان اليوم متقدمة صناعية كانت أم نامية في استر اتيجيات تنميتها

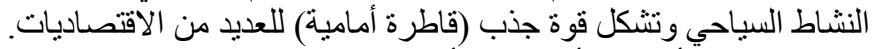

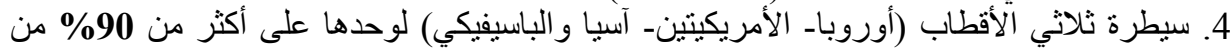

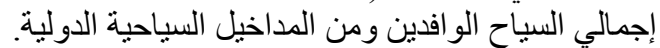

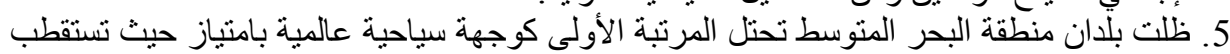
لوحدها ما يعادل نسبة 30\% من إجمالي السياح الو افدين عالميًا وكذا من حيث المئة المداخيل السياحية. 
6. تعرف السياحة منافسة شديدة بين البلدان و الأقاليم للترويج للوجهات السياحية العالمية الجديدة، خاصة

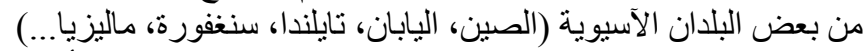

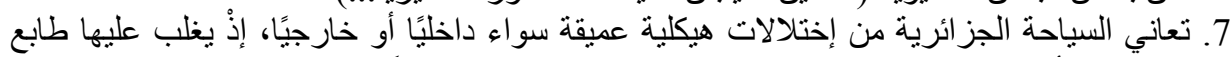

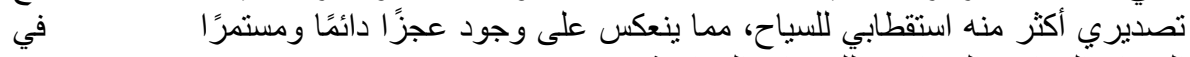

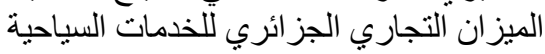

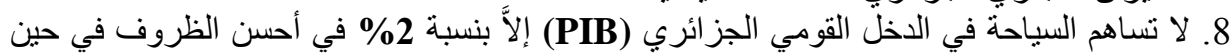

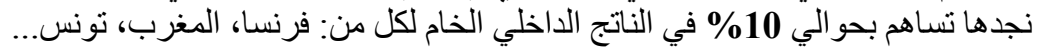

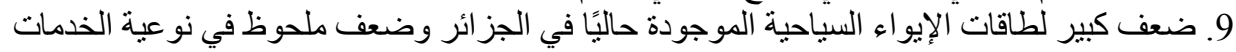

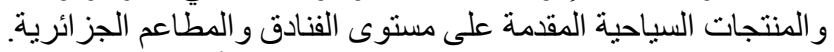

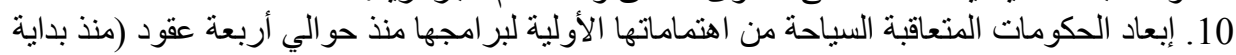
عقد الثمانينات من القرن الماضيك).

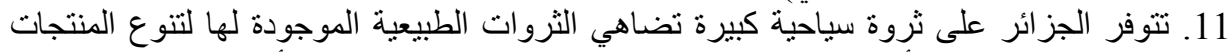
السياحية التي ممكن أن تقدمها وتعطيها ميزة تنافي التهية على على مستوى الأسواق العالمية خاصة في مجال (السياحة الشاطئية و الحموية و الصئ والصحر اوية....)

المقترحات: بناءًا على النتائج المتوصل إليها نقدم الاقتر احات التالية: 1. تنجيع المسعى الحكومي في إدر اج السياحة من أولويات القطاعات التي تعتمد عليها الدولة الجزائرية في تنميتها للآفاق الزمنية المستقبلية.

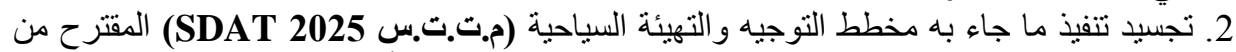
طرف وزارة السياحة الجزائرية، خاصة بالإسراع في إنشاء الأقطاب السبعة والقاء القرى السياحية

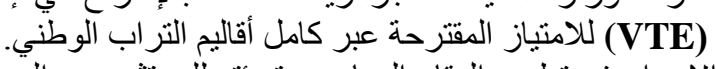
3. الإسر اع في تطهير العقار السياحي وتهيئته للمستشمرين واليم المرقين العين في مجال السياحة و مر افقتهم بتقديم

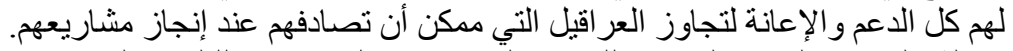

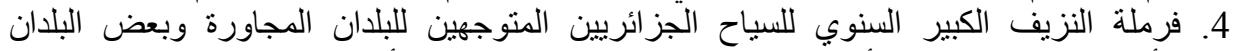

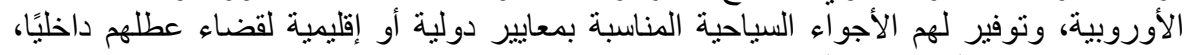

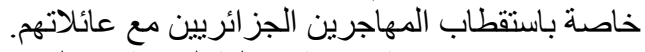

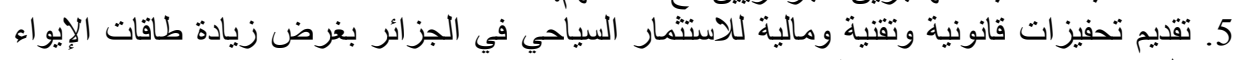
السياحي (فنادق- قرى سياحية....). 6. القيام بالترويج للوجهة السياحية الجزائرية باستخدام عناصر الجذب البية السياحي المميزة للجزائر في

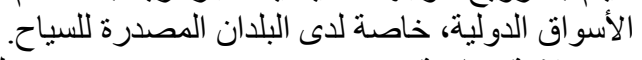

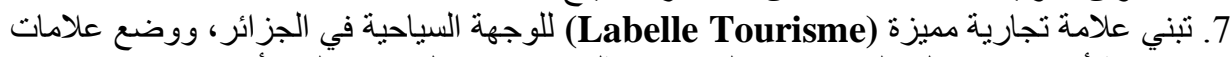

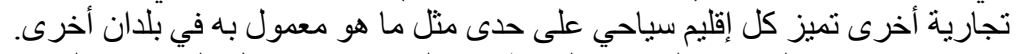

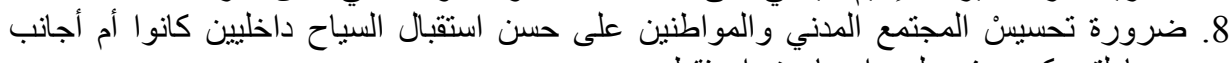

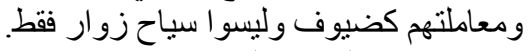

9. تجسيد مخطط النو عية السياحية Plan Qualité Tourisme (PQT). 10. تكثيف التكوين العلمي والمهني للعاملين في قطاع السياحة في مجالات: الفندقة، الإطعام، اللغات، الإرشاد السياحي..

11 1. إعطاء صلاحياتّ أكبر للجماعات المحلية خاصة البلديات للتدخل في مجال السياحة بصيانة المعالم

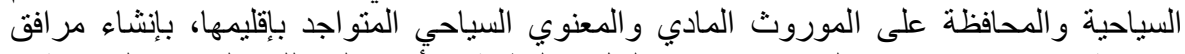

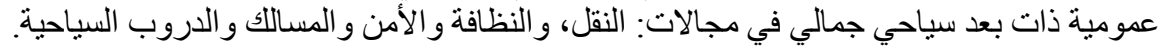


(1)- Jean- Pierre Lozato - Giotart, Michel Balfet, Management du Tourisme :

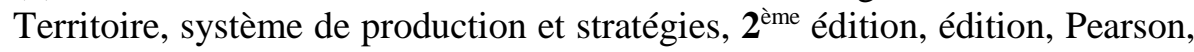
Paris, 2014, P.4.

(2)- Cécile Clergeau en collaboration avec Olivier Glasberg et Philippe Violier, Mangement des entreprises du tourisme, stratégie et organisation, édition Dunod, Paris, 2014, P.10.

(3)- حمزة عبد الحليم در ادكه وآخرون، مبادئ السياحة، الطبعة الأولى، عمان، 2016، ص ص

(4)- Jean-Pierre Lozato - Giotart, Géographie du tourisme, Pearson éduction, France, Paris, 2003, PP. 34-36.

(5)- مرزوق عايد القعيد وآخرون، مبادئ السياحة، الطبعة الأولى، إثراء للنشر و التوزيع بالأردن،

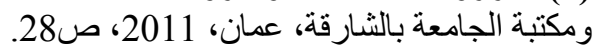

(6)- Jean-Pierre Lozato - Giotart, Michel Balfet, op-cit, P.6.

$$
\text { (7)- مرزوق عايد القعيد وآخرون، مرجع سبق ذكره، ص95. }
$$

(8)- David Weaver, Laura Lawton, Tourism Management, Fourth edition, edition Willey, Australia, 2010, P.13.

(9)- Annual Report World tourism Organization, 2016, UNWTO, P.7.

(10)- Jean-Pierre Lozato - Giotart, Géographie du tourisme, op-cit, P.37.

(11)- David Weaver Laura Lawton, op-cit, P. 82.

الاردة) - زيد منير عبوي،إدارة المنشآت السياحية والفندقية،الطبعة الأولى،الجامعة

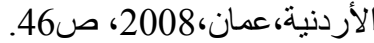

(13)- Cécil Clergeau, Management des entreprises du tourisme, op-cit, P. 129.

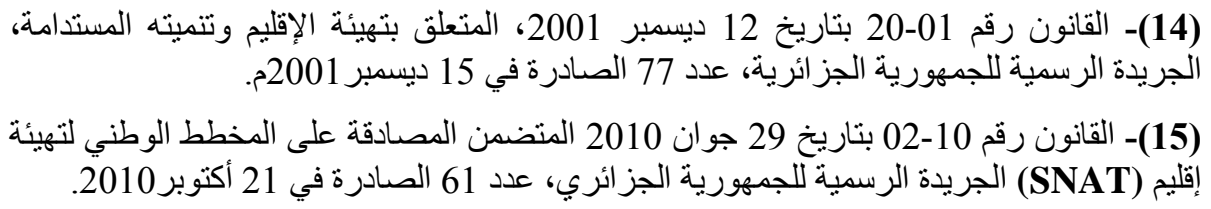

(16)- Agence Nationale de développement de l'investissement (ANDI), Alger, 2017.

(17)- محمد البنا، اقتصاديات السياحة و الفندقة، الدار الجامعية، الإسكندرية، 2009، ص ص 162، 


$$
\begin{aligned}
& \text { (1) - الديو ان الوطني للإحصاء (ONS)، الجز ائر، } 2017
\end{aligned}
$$

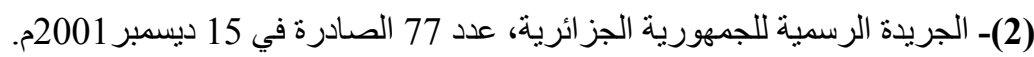

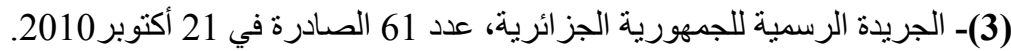

$$
\begin{aligned}
& \text { (4)- حمزة عبد الحليم در ادكه وآخرون، مبادئ السياحة، الطبعة الأولى، عمان، } 2016 . \\
& \text { (5)- مرزوق عايد القعبد وآخرون، مبادئ السياحة، الطبعة الأولى، إثراء للنشر و التوزيع بالأردن، }
\end{aligned}
$$

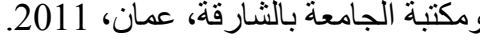

$$
\begin{aligned}
& \text { (6)- زيد منير عبوي، إدارة المنثآت السياحية والفندقية، الطبعة الأولى، الجامعة الأردنية، عمان، } 2008 . \\
& \text { (7)- محمد البنا، اقتصاديات السياحة والفندقة، الدار الجامعية، الإسكندرية، } 2009 . \\
& \text { (8) - وزارة تهيئة الإقليم و البيئة و السياحة، المخطط التوجيهي للتهيئة السياحية (م.ت.ت.س SDAT } \\
& .2008(2025 \\
& \text { باللغة الأنجليزبة }
\end{aligned}
$$

(1)- Annual Report World tourism Organization, 2016, UNWTO.

(2) - Annual Report World tourism Organization, 2017, UNWTO.

(3) - World Tourisme Organization (UNWTO), July 2017.

\section{بللغة الفرنسبة}

(1)- Agence Nationale de développement de l'investissement (ANDI), Alger, 2017.

(2)- Cécile Clergeau en collaboration avec Olivier Glasberg et Philippe Violier, Mangement des entreprises du tourisme, stratégie et organisation, édition Dunod, Paris, 2014.

(3)- David Weaver, Laura Lawton, Tourism Management, Fourth edition, edition Willey, Australia, 2010.

(4)- Jean- Pierre Lozato - Giotart, Michel Balfet, Management du Tourisme : Territoire, système de production et stratégies, $\mathbf{2}^{\text {ème }}$ édition, édition, Pearson, Paris, 2014.

(5)- Jean-Pierre Lozato - Giotart, Géographie du tourisme, Pearson éduction, Paris, 2003.

(6) - Jean - Loui Caccomo, Fondements d'économie du Tourisme, 1 ère édition, édition

De Boek, Bruxelles, 2007.

(7) - Laurent BOTTI, Nicolas PEPOCH, Bernardin SOLANDRASANA, Economie du

Tourisme, édition Dunod, Paris, 2013. 